\title{
Zinc- and Tin-Mediated C-C Coupling Reactions of Metalated (2-Pyridylmethyl)(trialkylsilyl)amines - Mechanistic, NMR Spectroscopic, and Structural Studies
}

\author{
Matthias Westerhausen, ${ }^{*[a]}$ Tobias Bollwein, ${ }^{[a]}$ Nikolaos Makropoulos, ${ }^{\text {[a] }}$

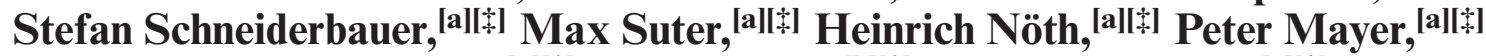 \\ Holger Piotrowski, ${ }^{[a \mid[\$ 1}$ Kurt Polborn, ${ }^{|b| \mid \ddagger]}$ and Arno Pfitzner ${ }^{[\mathrm{cll} \ddagger]}$
}

Keywords: Amides / C-C coupling / Magnesium / Metalations / Metallacycles / Pyridyl ligands / Tin / Zinc

The zincation of (2-pyridylmethyl)(triisopropylsilyl)amine (1) gives dimeric methylzinc (2-pyridylmethyl)(triisopropylsilyl)amide (2). Further addition of dimethylzinc to a toluene solution of $\mathbf{2}$ at raised temperatures yields the $\mathrm{C}-\mathrm{C}$ coupling product [1,2-dipyridyl-1,2-bis(triisopropylsilylamido)ethane]bis(methylzinc) (3). Heating of molten 2, or UV irradiation of $\mathbf{2}$, results in the formation of $\mathbf{3}$ and zinc bis[(2-pyridylmethyl)(triisopropylsilyl)amide] (4). The reaction between the zinc dihalide complexes of $\mathbf{1}[\mathbf{5 a}(\mathrm{X}=\mathrm{Cl})$ and $\mathbf{5 b}(\mathrm{X}=\mathrm{Br})]$ and methyllithium yields the $\mathrm{C}-\mathrm{C}$ coupling product $\mathbf{3}$ and the heteroleptic complex 2, observed by NMR spectroscopy. During this reaction, zinc metal precipitates. The magnesiation of $\mathbf{1}$ with dibutylmagnesium gives magnesium bis[(2-pyridylmethyl)(triisopropylsilyl)amide] (6) in a quantitative yield. Subsequent addition of dimethylmagnesium results in a dismutation reaction and the formation of heteroleptic methylmagnesium (2-pyridylmethyl)(triisopropylsilyl)amide (7). Treatment of $\mathbf{1}$ with dimethylmagnesium also gives 7 . This complex slowly undergoes an intramolecular metalation during which dark red single crystals of (tetrahydrofuran)magnesium 2-(triisopropylsilylamidomethylidene)-1-azacyclohexa-3,5-dien-1-ide (8) precipitate. In this compound the aromaticity of the pyridyl fragment is abolished. The magnesiation of (tert-butyldimethylsilyl)(2-pyridylmethyl)amine (I) proceeds quantitatively to give methylmagnesium (tert-bu- tyldimethylsilyl)(2-pyridylmethyl)amide (9). This compound also undergoes an intramolecular metalation reaction, which results in the loss of the aromaticity of the pyridyl substituent and the formation of (tetrahydrofuran)magnesium 2-(tertbutyldimethylsilylamidomethylidene)-1-azacyclohexa-3,5dien-1-ide (10). The metalation of 1 with tin(II) bis[bis(trimethylsilyl)amide] yields [bis(trimethylsilyl)amido]tin(II) (2-pyridylmethyl)(triisopropylsilyl)amide (11). The elimination of tin metal occurs even at room temperature, and the $\mathrm{C}-\mathrm{C}$ coupling product [1,2-dipyridyl-1,2-bis(triisopropylsilylamido)ethane]tin(II) (12) is formed. The metalation of (tert-butyldimethylsilyl)(2-pyridylmethyl)amine with $\mathrm{Sn}\left[\mathrm{N}\left(\mathrm{SiMe}_{3}\right)_{2}\right]_{2}$ gives [bis(trimethylsilyl)amido]tin(II) (tert-butyldimethylsilyl)(2-pyridylmethyl)amide (13). Within a few minutes, precipitation of tin metal takes place and the $\mathrm{C}-\mathrm{C}$ coupled product [1,2-bis(tert-butyldimethylsilylamido)-1,2-dipyridylethane]tin(II) (14) is produced. In order to examine the importance of the pyridyl ligand for the $\mathrm{C}-\mathrm{C}$ coupling reactions, zinc bis[N-(tert-butyldimethylsilyl)benzylamide] (15) was prepared by means of the metathesis reaction between lithium $N$-(tert-butyldimethylsilyl)benzylamide and zinc(II) halide. Treatment of $\mathbf{1 5}$ with dimethylzinc yields heteroleptic methylzinc $N$-(tert-butyldimethylsilyl)benzylamide (16). Refluxing of $\mathbf{1 6}$ with an excess of dimethylzinc in toluene does not give any $\mathrm{C}-\mathrm{C}$ coupling reactions.

\section{Introduction}

A novel oxidative $\mathrm{C}-\mathrm{C}$ coupling reaction subsequent to zincation of (tert-butyldimethylsilyl)(2-pyridylmethyl)amine

[a] Department Chemie, Ludwig-Maximilians-Universität München,

Butenandtstraße 9 (Haus D), 81377 München, Germany Fax: (internat.) + 49-(0)89/2180-7867 E-mail:maw@cup.uni-muenchen.de

[b] Department Chemie, Ludwig-Maximilians-Universität München, Butenandtstraße 13 (Haus F), 81377 München, Germany

[c] Anorganische Chemie II, Universität Siegen, 57068 Siegen, Germany

Fax: (internat.) + 49-(0)271/7402555

[*] Crystal structure determinations.
(I) has been found. ${ }^{[1]}$ The metalation of amine I with dimethylzinc yielded dimeric methylzinc (tert-butyldimethylsilyl)(2-pyridylmethyl)amide (II), according to Scheme 1. Either thermal decomposition or the addition of another equivalent of dimethylzinc at elevated temperatures then resulted in the oxidative $\mathrm{C}-\mathrm{C}$ coupling reaction and hence in the formation of [1,2-bis(tert-butyldimethylsilylamido)-1,2dipyridylethane]bis(methylzinc) (III) and the precipitation of zinc metal. The thermal decomposition of II also resulted in the formation of amine $\mathbf{I}$, which was zincated by II still present to give zinc bis[(tert-butyldimethylsilyl)(2-pyridylmethyl)amide] (IV), according to Scheme 2. ${ }^{[1]}$ 


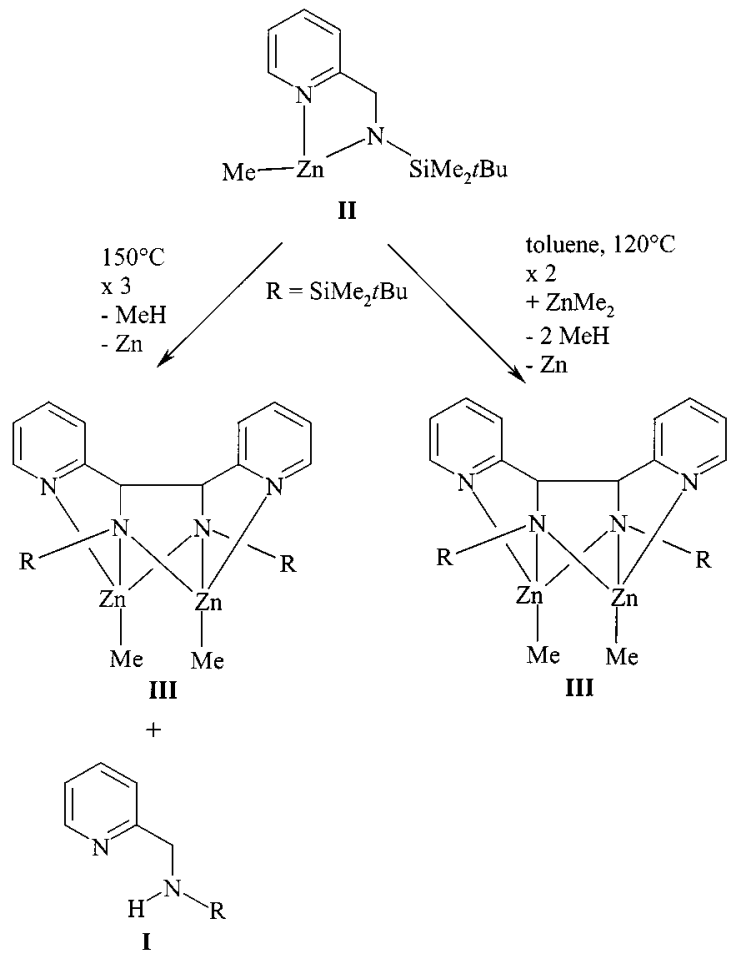

Scheme 1

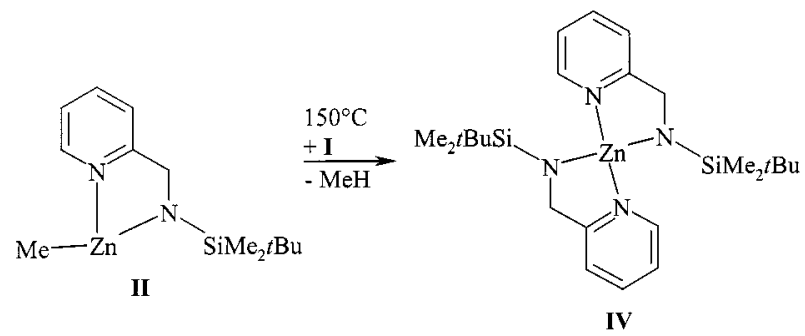

Scheme 2

The reaction between $N, N^{\prime}$-di(tert-butyl)-1,4-diazabutadiene and dialkylzinc offered three different possible reaction pathways: ${ }^{[2,3]} C$-alkylation (A) ${ }^{[4,5]}$ radical formation $(\mathbf{B}),{ }^{[6,7]}$ and $N$-alkylation $(\mathbf{C})^{[4,5]}$ after a homolytic $\mathrm{Zn}-\mathrm{C}$ bond cleavage. An overview of these reactions is given in Scheme 3. The radicals $\mathbf{B}$ were in equilibrium with the dimeric species, as shown in this reaction diagram..$^{[2,8,9]}$ Mechanistically the formation of the $\mathrm{C}-\mathrm{C}$-coupled dimer can be explained by recombination of radicals.

This mechanism is not transferable to the oxidative $\mathrm{C}-\mathrm{C}$ coupling reaction described here, for several reasons. During the zincation and subsequent $\mathrm{C}-\mathrm{C}$ coupling, no radicals were detected by ESR spectroscopy and neither was a monomer-dimer equilibrium observed. In order to investigate the mechanism of the oxidative $\mathrm{C}-\mathrm{C}$ coupling reaction shown in Scheme 1, it was necessary to address several questions: the influence of the steric hindrance of the $N$ bonded trialkylsilyl group, the standard potential $E^{0}(\mathrm{M} /$ $\mathrm{M}^{2+}$ ) of the metalation reagent, and the role of the pyridyl substituent.

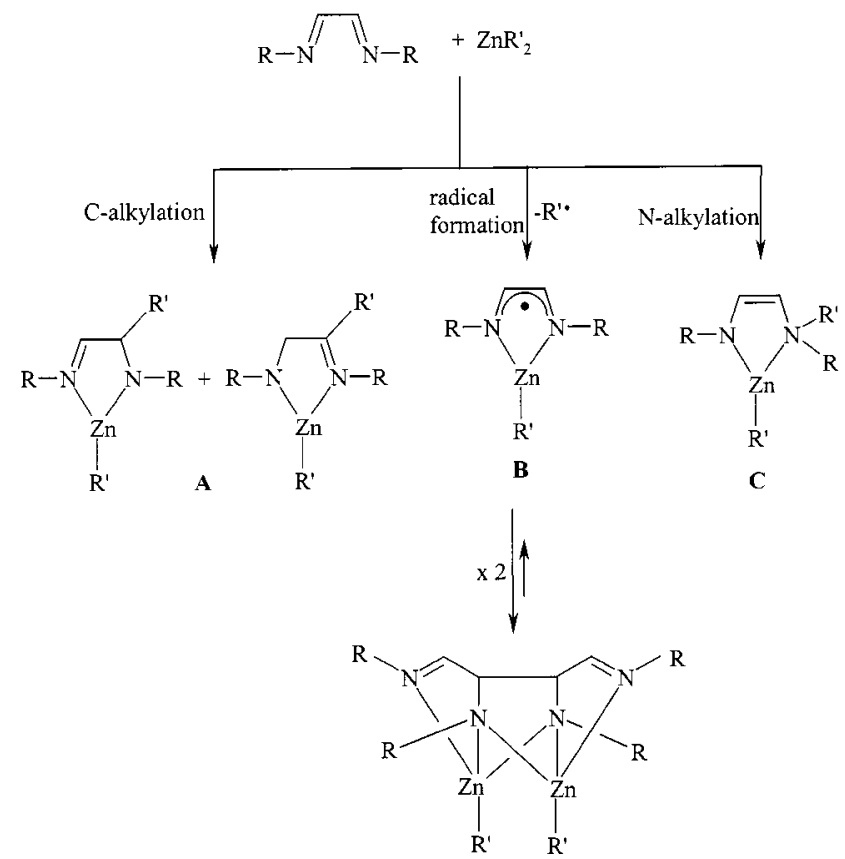

Scheme 3

\section{Results and Discussion}

\section{Synthesis and Mechanistic Studies}

It has already been shown that methylzinc (tert-butyl)(2pyridylmethyl)amide undergoes a monomer/dimer equilibrium favoring the dimeric molecule VI (Scheme 4), ${ }^{[2,8]}$ which has also been structurally characterized. ${ }^{[9]}$ The substitution of the tert-butyl group for a trialkylsilyl substituent results in drastic changes in the chemical and physical behavior of these molecules. On one hand, the $N$-trialkylsilyl substitution prevents the monomerization process, while on the other a novel synthetic route to these tetradentate ligands in a quantitative yield is possible, by means of the $\mathrm{C}-\mathrm{C}$ coupling reaction.

\section{Influence of the Size of the Trialkylsilyl Substituents}

The lithiation of 2-(aminomethyl)pyridine and the subsequent metathesis reaction with chlorotriisopropylsilane yields (2-pyridylmethyl)(triisopropylsilyl)amine (1). The zincation of 1 gives dimeric methylzinc (2-pyridylmethyl)-
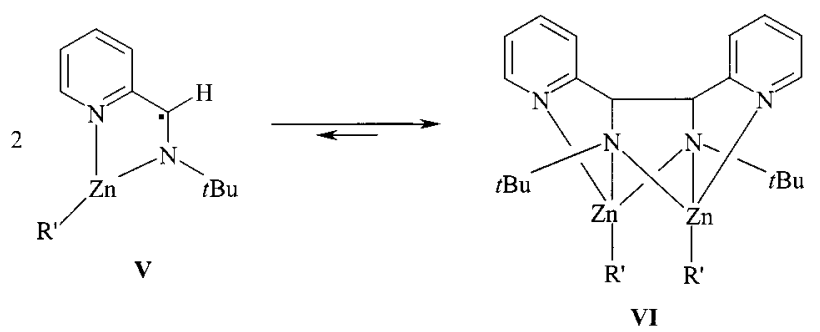

Scheme 4 
(triisopropylsilyl)amide (2), with a central $\mathrm{Zn}_{2} \mathrm{~N}_{2}$ ring. The addition of dialkylzinc to a solution of $\mathbf{2}$ in toluene at raised temperatures results in a $\mathrm{C}-\mathrm{C}$ coupling reaction and the formation of [1,2-bis(triisopropylsilylamido)-1,2-dipyridylethane]bis(methylzinc) (3). Heating of molten 2, or UV irradiation of 2, yields 3 and zinc bis[(2-pyridylmethyl)(triisopropylsilyl)amide] (4) in an equimolar ratio, together with zinc and methane. Compound $\mathbf{4}$ represents a structure similar to IV, the only difference being the substituents at the silicon atom.

The quantitative synthesis of $\mathbf{3}$ is achieved by means of a reaction between 1 and at least 1.5 equiv. of dimethylzinc. The mechanistic picture is presented in Scheme 5. The first step is the complexation of dimethylzinc by $\mathbf{1}$, as described below for the zinc dihalide complexes and similar to already published adducts. ${ }^{[6,10]}$ Subsequently, the amine moiety is zincated. The methylene groups are then metalated by a methylzinc moiety. Whether this zincation step happens intramolecularly (monomolecular) or intermolecularly (bimolecular or even higher order) is uncertain, especially in view of the fact that the compounds described above are dimeric both in the solid state and in solution. The relaxation of the anionic charge produces a bis(amide). However, this intermediate forms only at higher temperatures and was not observable in the zinc-mediated $\mathrm{C}-\mathrm{C}$ coupling reaction. At these temperatures, the zinc atom could be eliminated as $\mathrm{Zn}^{0}$, with (pyridylmethylidene)(trialkylsilyl)amine being formed. In the presence of additional dimethylzinc and another equivalent of $\mathbf{2}$, the $\mathrm{C}-\mathrm{C}$ coupling occurs immediately with evolution of methane (mass spectrometric identification) and precipitation of zinc metal (proof by X-ray powder diffraction ${ }^{[1]}$ ). Because of the dimeric nature of $\mathbf{2}$,

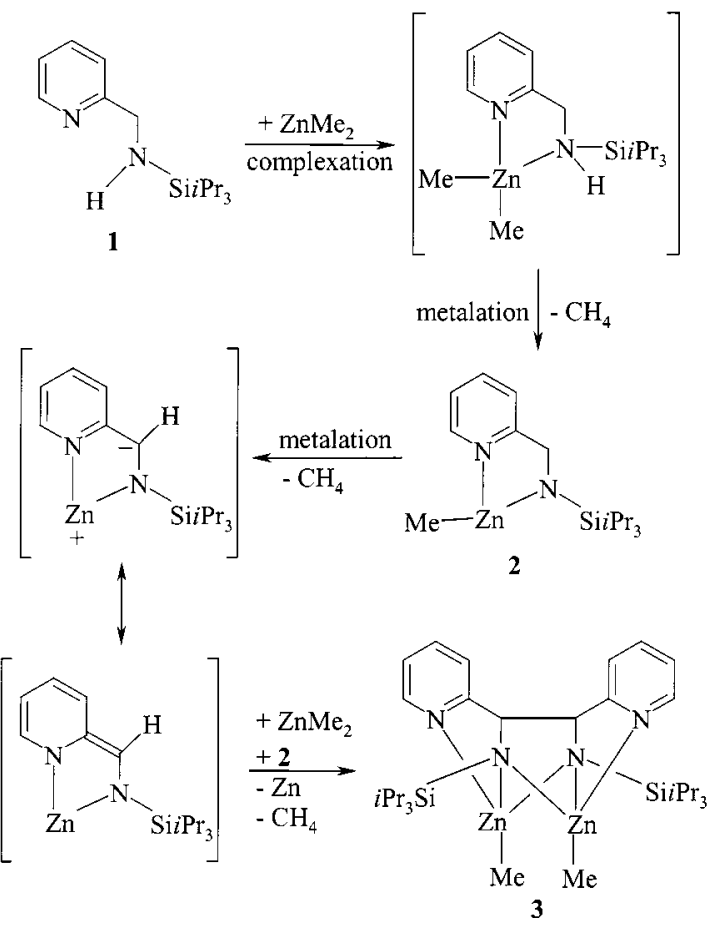

Scheme 5 only the $(R, R)$ and the $(S, S)$ isomers of $\mathbf{3}$ are formed, and no meso isomer is observed. The steric demand of the trialkylsilyl groups influences the conformation of the dimeric methylzinc (2-pyridylmethyl)(trialkylsilyl)amide as shown in Scheme 6 (structure types $\mathbf{D}$ and $\mathbf{E}$ ), but not the reactivity towards dimethylzinc.

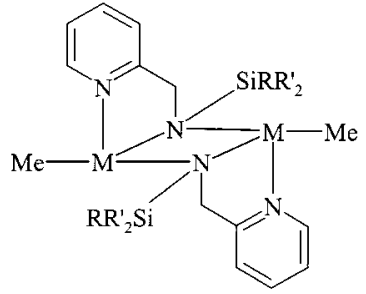

D

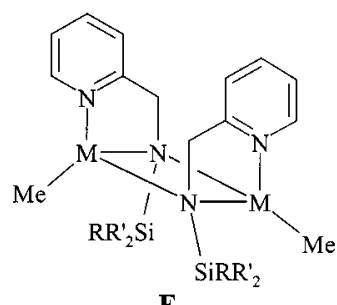

$\mathbf{E}$
Scheme 6. Schematic drawing of the two possible conformations D and $\mathbf{E}$ for the dimeric derivatives of the type $\left[\mathrm{R}-\mathrm{M}-\mathrm{N}\left(\mathrm{SiRR}_{2}{ }_{2}\right) \mathrm{CH}_{2}-\mathrm{py}\right]_{2}$ with $\mathrm{M}$ as $\mathrm{Zn}(2$ and II) and $\mathrm{Mg}(7$ and 9)

Mixing of compounds III and $\mathbf{3}$ in toluene does not afford the mixed compound with a triisopropylsilyl group at one nitrogen atom and a tert-butyldimethylsilyl substituent at the other, which we also interpret as support for the ionic mechanism. However, irradiation of this mixture does produce this mixed derivative, most probably through a $\mathrm{C}-\mathrm{C}$ bond cleavage, as shown for the equilibrium in Scheme 4 for the $N$-tert-butyl derivative.

Another possibility for the synthesis of $\mathbf{3}$ is shown in Scheme 7. Treatment of 1 with zinc dihalides yields the corresponding adducts $\mathbf{5 a}(\mathrm{X}=\mathrm{Cl})$ and $\mathbf{5 b}(\mathrm{X}=\mathrm{Br})$, which are only partly soluble in common organic solvents. The addition of methyllithium to $\mathbf{5 b}$ results in the formation of the $\mathrm{C}-\mathrm{C}$ coupling product $\mathbf{3}$ and the heteroleptic complex 2, as observed by NMR spectroscopy. During this reaction, zinc metal precipitates in accordance with the proposed mechanism.

\section{Influence of the Standard Potential $E^{0}\left(\mathrm{M} / \mathrm{M}^{2+}\right)$}

If the reaction were to be performed with other metals, other pathways should be followed, depending on the potential $E^{0}\left(\mathrm{M} / \mathrm{M}^{2+}\right)$, which for zinc is $-0.7626 \mathrm{~V} \cdot{ }^{[11]} \mathrm{In}$ order to investigate the reaction mechanism, the less noble magnesium $\left[E^{0}\left(\mathrm{Mg} / \mathrm{Mg}^{2+}\right)=-2.356 \mathrm{~V}^{[11]}\right]$ and the nobler tin $\left[E^{0}\left(\mathrm{Sn} / \mathrm{Sn}^{2+}\right)=-0.137 \mathrm{~V}^{[11]}\right]$ were applied. The magnesiation of $\mathbf{1}$ with dibutylmagnesium gives magnesium bis[(2pyridylmethyl)(triisopropylsilyl)amide] (6) in a quantitative yield. Subsequent addition of dimethylmagnesium results in a dismutation reaction and the formation of heteroleptic methylmagnesium (2-pyridylmethyl)(triisopropylsilyl)amide (7). Treatment of 1 with dimethylmagnesium in an equimolar ratio gives mainly 7; the reaction solution turns dark, however. Reduction of the volume and cooling to approximately $5{ }^{\circ} \mathrm{C}$ results in the precipitation of dark red, single crystals of (tetrahydrofuran)magnesium 2-[(triisopropylsilyl)amidomethylidene]-1-azacyclohexa-3,5-dien-1-ide (8) in a rather low yield, embedded in a dark oil. The first reaction step is clearly the metalation of the amine $\mathbf{1}$, followed 


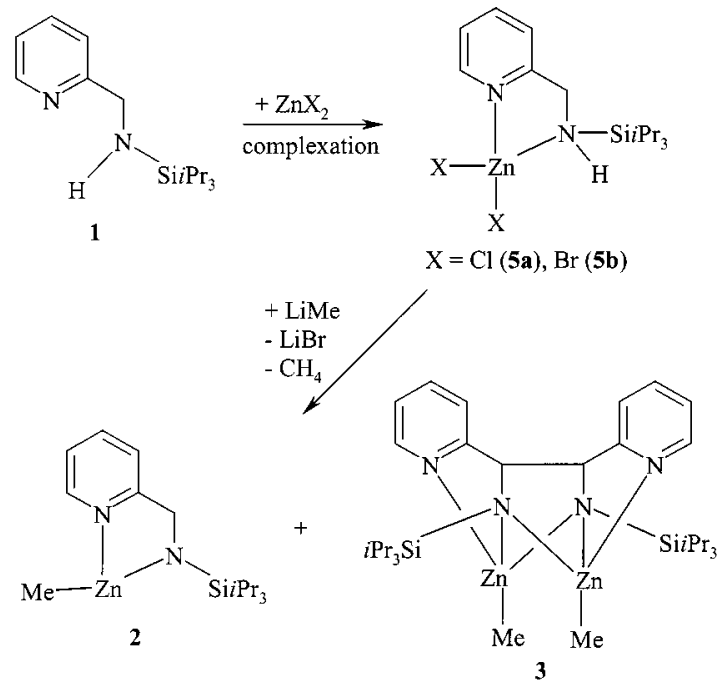

Scheme 7

by a further metalation of the methylene group. The anionic charge is then transferred to the pyridyl nitrogen atom, thus forming a bis(amide) as shown in Scheme 8. The stronger metalation power ${ }^{[12]}$ of a magnesium-bonded methyl group allows intramolecular $\mathrm{H}$ abstraction and the breakdown of the aromaticity of the pyridyl moiety at lower temperatures. The reduced aromatic character of $C$-bonded pyridyl moieties is already well known in the case of [bis(2pyridyl)methyl]lithium..$^{[13-15]}$ No precipitation of magnesium metal is observed in the course of this reaction. During the zincation of $\mathbf{1}$, no similar zinc bis(amide) was detected, because on the one hand elevated temperatures are necessary for the metalation of the methylene fragment and on the other hand the reduction of the zinc dication is more easily accessible than that of the magnesium dication. Complex 8, if dissolved in common organic solvents, decomposes into a variety of as yet unidentified products, which prevents spectroscopic characterization.

The magnesiation of (tert-butyldimethylsilyl)(2-pyridylmethyl)amine (I) proceeds quantitatively, to give methylmagnesium (tert-butyldimethylsilyl)(2-pyridylmethyl)amide (9). Even though this metalation is performed in THF, 9 crystallizes from a toluene solution isotypically to the corresponding zinc derivative, ${ }^{[1]}$ as a dimer without coordination of further neutral coligands. This compound undergoes an intramolecular metalation reaction, which results in the loss of the aromaticity of the pyridyl substituent and the formation of (tetrahydrofuran)magnesium 2-[(tert-butyldimethylsilyl)amidomethylidene]-1-azacyclohexa-3,5-dien-1ide (10). In a concentrated THF solution, dark red crystals, containing both the compounds $\mathbf{9}$ and $\mathbf{1 0}$ in an equimolar ratio, precipitate at $5{ }^{\circ} \mathrm{C}$ within $3 \mathrm{~d}$. This magnesiation step occurs even in the dark and at low temperatures. Attempts to crystallize pure $\mathbf{1 0}$ were not successful. Thanks to this cocrystallization during the intramolecular magnesiation process, $\mathbf{9}$ and $\mathbf{1 0}$ were removed from the reaction solution environment, which allowed their molecular structures to
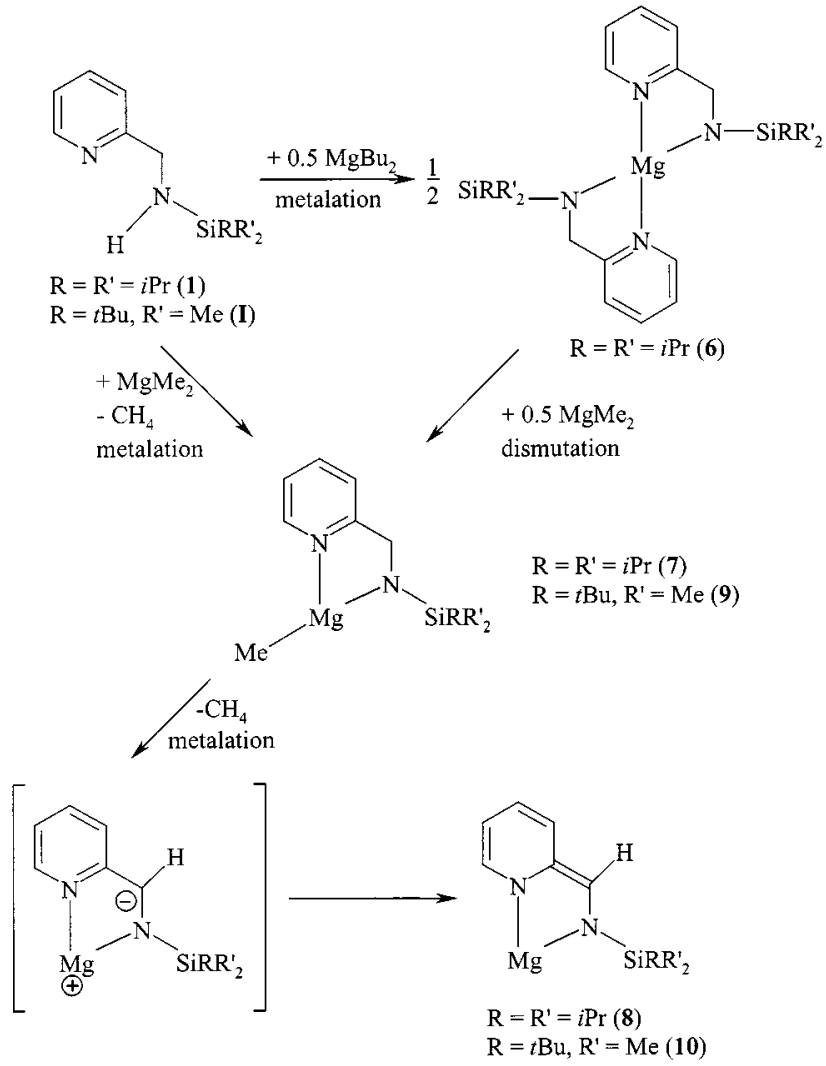

Scheme 8

be crystallographically determined, since the crystalline material constituting $\mathbf{1 0}$ decomposes very slowly in the solid state. In solution, however, as yet unknown decomposition reactions occur.

The metalation of $\mathbf{1}$ with tin(II) bis[bis(trimethylsilyl)amide ${ }^{[16-20]}$ yields a green solution of [bis(trimethylsilyl)amido]tin(II) (2-pyridylmethyl)(triisopropylsilyl)amide (11). The elimination of tin metal occurs even at room temperature, as proven by X-ray powder diffraction analysis (Figure 1). In an equimolar quantity, the $\mathrm{C}-\mathrm{C}$ coupling product tin(II) 1,2-dipyridyl-1,2-bis(triisopropylsilylamido)ethane (12) forms according to Scheme 9. Because of the size of the $\mathrm{Sn}^{2+}$ cation and the stereochemical activity of the lone pair, only one metal center is coordinated to this tetradentate ligand, through three nitrogen atoms. The magnetic equivalence of both pyridyl groups can be explained by a fast (on the NMR timescale) exchange reaction. NMR spectroscopic investigation of the crystals shows the presence of a small amount of the meso isomer 12', because the fixation of the geometry is less restrictive in regard to the reaction pathway due to the mononuclearity of these tin(II) complexes.

The smaller tert-butyldimethylsilyl group at the amide moiety gives products similar to those described above. The metalation of (tert-butyldimethylsilyl)(2-pyridylmethyl)amine I with $\mathrm{Sn}\left[\mathrm{N}\left(\mathrm{SiMe}_{3}\right)_{2}\right]_{2}$ gives [bis(trimethylsilyl)amido]tin(II) (tert-butyldimethylsilyl)(2-pyridylmethyl)amide (13). Within a few minutes, the precipitation of tin 


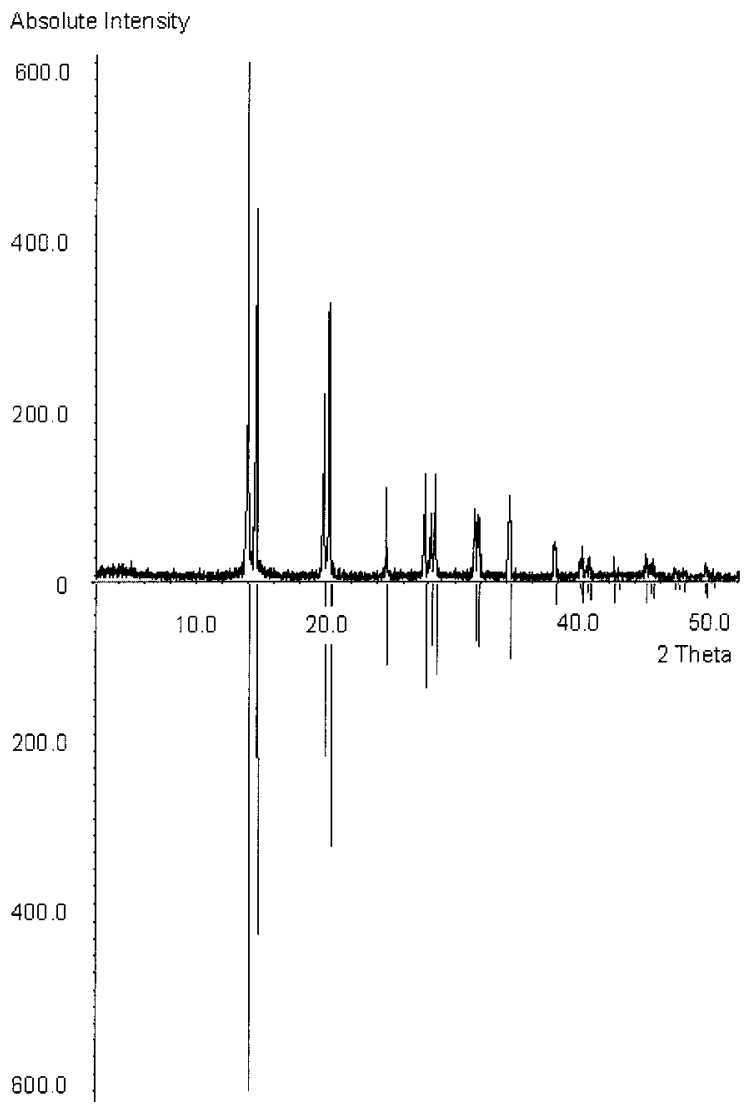

Figure 1. X-ray powder diffractogram of tin that precipitated during the $\mathrm{C}-\mathrm{C}$ coupling reactions (top) and the reference line spectrum (bottom)

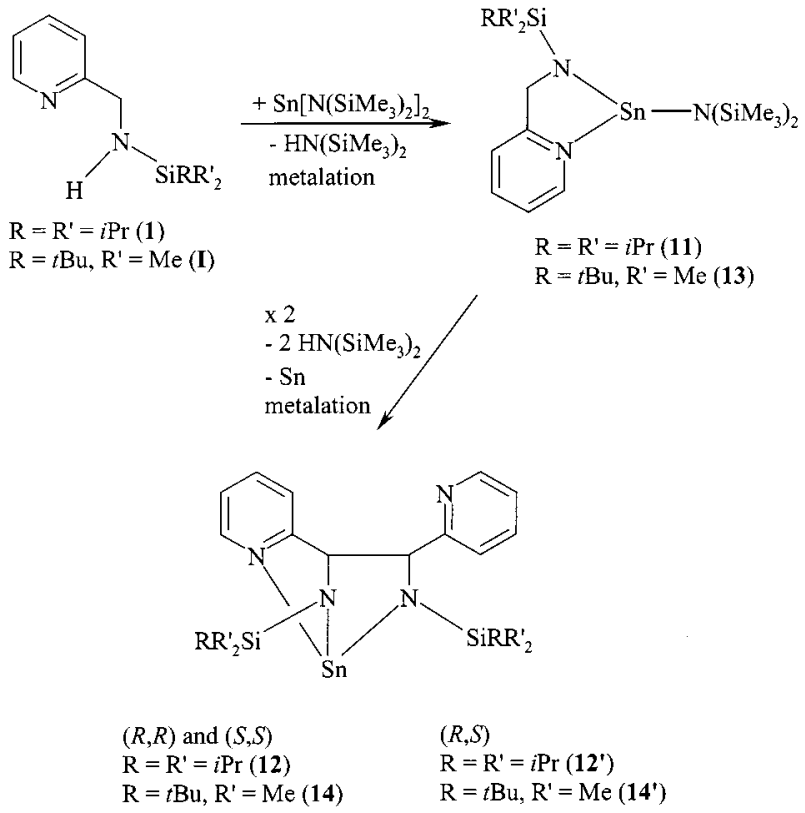

Scheme 9

metal and the $\mathrm{C}-\mathrm{C}$ coupling reaction begin. Thanks to the less crowded trialkylsilyl substituent, the $(R, R)$ and $(S, S)$ isomers $\mathbf{1 4}$ are formed together with a small quantity of the meso form $\mathbf{1 4}^{\prime}$.
All these $\mathrm{C}-\mathrm{C}$ coupling products are colorless and no equilibrium similar to the reaction described in Scheme 4 was observed. Solutions of these derivatives in toluene and heptane showed no EPR signal, and so there was no indication of a radical mechanism. We interpret all these findings in terms of the involvement of a polar reaction mechanism.

\section{Importance of the Pyridyl Fragment}

The pyridyl substituent could be important for this reaction in two ways. On the one hand, it might function as an anchor group to bind dimethylzinc and thus to enforce a close contact between the metalating reagent and the amine. On the other, the reaction mechanism involves a step in which the aromaticity of the pyridyl substituent is disturbed and a bis(amide) is formed. Therefore, the use of an $\mathrm{N}$ silylated benzylamine (formal replacement of the pyridyl nitrogen atom by a $\mathrm{CH}$ fragment) was investigated. This change strongly decreased the reactivity of (benzyl)(tert-butyldimethylsilyl)amine towards dimethylzinc. The zincation did not offer access to the corresponding zinc amides.

In order to examine the importance of the pyridyl ligand for the $\mathrm{C}-\mathrm{C}$ coupling reactions, zinc bis[(benzyl)(tert-butyldimethylsilyl)amide] (15) was prepared by lithiation of (benzyl)(tert-butyldimethylsilyl)amine $(\mathbf{V})^{[21]}$ and the subsequent metathesis reaction with zinc(II) halide according to Scheme 10. Treatment of $\mathbf{1 5}$ with dimethylzinc yielded heteroleptic methylzinc (benzyl)(tert-butyldimethylsilyl)amide (16). ${ }^{[22]}$

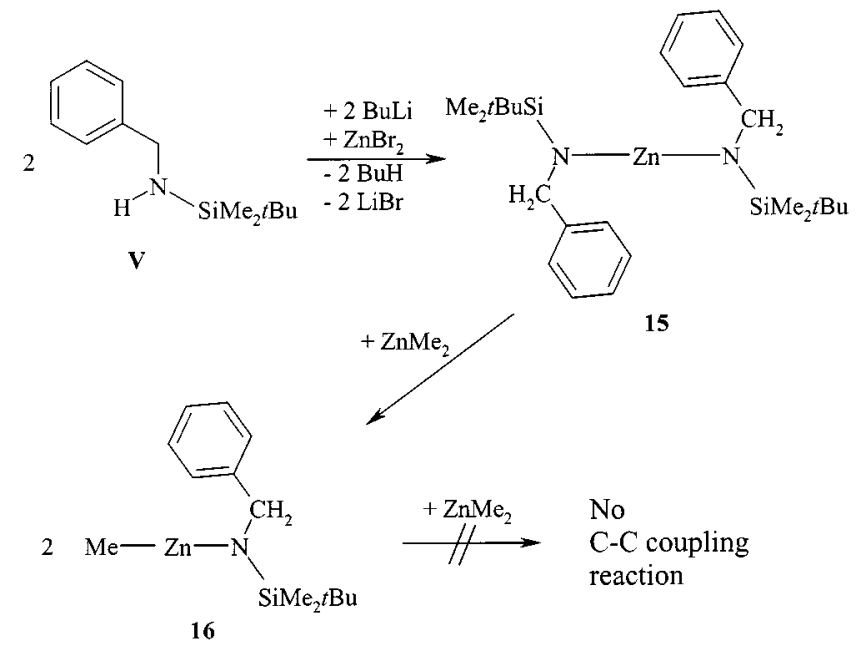

Scheme 10

Compound 16 behaves as a characteristic heteroleptic alkylzinc amide, as is well known for a wide variety of compounds of the general type $\mathrm{R}-\mathrm{Zn}-\mathrm{NR}^{\prime} \mathrm{R}^{\prime \prime}$ (see examples in the literature $\left.{ }^{[23-26]}\right)$. No $\mathrm{C}-\mathrm{C}$ coupling reaction between 16 and excess dimethylzinc was observed, even in refluxing toluene.

From these observations, we conclude that a derivative with a disturbed aromatic character in the pyridyl fragment seems to play the key role in this mechanism. For the $\mathrm{C}-\mathrm{C}$ coupling reaction, the presence of the methylpyridyl moiety 
is essential, whereas the steric demand of the $N$-bonded trialkylsilyl substituent is only of secondary importance. The standard potential determines the reaction conditions for the $\mathrm{C}-\mathrm{C}$ coupling. Whereas mild conditions are sufficient for the use of tin(II), the reaction solutions had to be heated to perform the coupling with zinc(II). Magnesium was not able to initiate the $\mathrm{C}-\mathrm{C}$ bond formation but we were therefore able in this case to determine the crystal structures of molecules that most probably serve as intermediates in the metalation reactions with zinc(II) and tin(II) reagents.

\section{Structural Investigations}

Figure 2 shows the molecular structure and numbering scheme of 2 . The crystallographic $C_{2}$ axis generates the second half of the molecule; the symmetry-related atoms are marked with primes. Scheme 7 shows the possible conformations for dimeric methylzinc (2-pyridylmethyl)(trialkylsilyl)amides. Whereas type $\mathbf{D}$ is already known for the $N$ (tert-butyldimethylsilyl)-substituted derivative ${ }^{\mathbf{I I}}{ }^{[1]}$ compound $\mathbf{2}$ crystallizes in structure type E. However, the conformation of the dimer is without importance for the reactivity in the $\mathrm{C}-\mathrm{C}$ coupling reaction. The central feature is the slightly folded $\mathrm{Zn}_{2} \mathrm{~N}_{2}$ ring (folding angle $167.1^{\circ}$ ) with $\mathrm{Zn}-\mathrm{N}$ bond lengths of approximately $211 \mathrm{pm}$ (Table 1 ). The transannular $\mathrm{Zn1} \cdots \mathrm{Zn} 1^{\prime}$ contact lies at $284.7 \mathrm{pm}$.

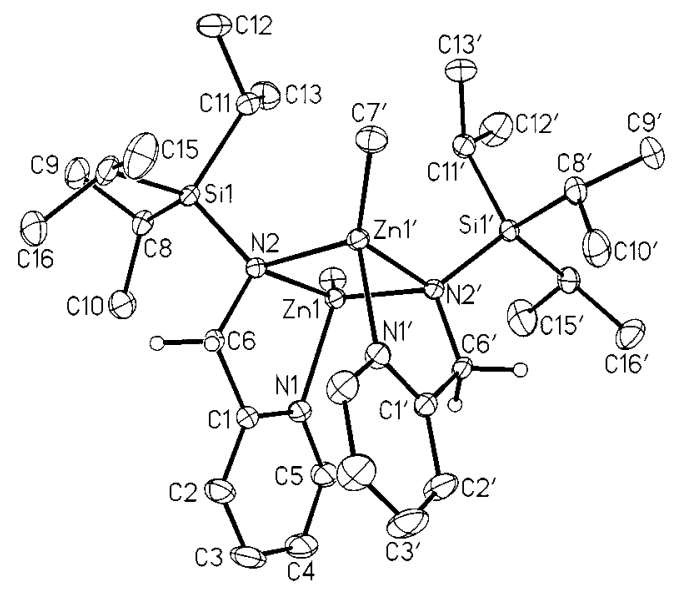

Figure 2. Molecular structure of 2; the ellipsoids represent $40 \%$ probability; atoms generated by the crystallographic $C_{2}$ symmetry $(-x, y,-z+1.5)$ are marked with apostrophes; the hydrogen atoms are omitted for clarity, with the exception of those at $\mathrm{C} 6 / \mathrm{CG}^{\prime}$

Figure 3 represents the molecular structure of 3 . The numbering scheme coincides with that of $\mathbf{2}$ and thus offers the possibility of direct comparison of the structural parameters (Table 1). The $\mathrm{C}-\mathrm{C}$ coupling of the bidentate anions results in the formation of both the $(R, R)$ - and the $(S, S)$ 1,2-bis(pyridyl)-1,2-bis(triisopropylsilylamido)ethane dianions. Thanks to the crystallographically enforced inversion center, both of these isomers are included in the investigated single crystals, whereas no $(R, S)$ isomer was observed either in the crystalline state or in solution.

The $\mathrm{Zn}-\mathrm{N}$ bonds of the pyridine moiety are elongated in comparison to those in the sterically unhindered (bipyr- idine- $N, N^{\prime}$ )zinc dichloride, with values of $206 \mathrm{pm} \cdot{ }^{[27]}$ In the pyridine complex bis(1,4-dihydropyridyl)bis(pyridineN)zinc, ${ }^{[28]}$ on the other hand, $\mathrm{Zn}-\mathrm{N}$ values of 198 and 213 pm have been observed for the anionic and the neutral ligands, respectively. Enhanced steric demand results in a further elongation of this bond, as shown for (bipyridine$N, N^{\prime}$ ) bis[bis(trimethylsilyl)methyl]zinc. ${ }^{[29]}$

The $\mathrm{C} 6-\mathrm{C}^{\prime}$ bond formation increases the intramolecular steric strain, as is also demonstrated by the $\mathrm{C} 6-\mathrm{C}^{\prime}{ }^{\prime}$ bond length of $160 \mathrm{pm}$, a value in the same range as, for example, strongly strained [1.1.1]propellanes. ${ }^{[30]}$ A slightly smaller value was previously found by van Koten and coworkers for compound VI [R = Et, 157.0(8) $\mathrm{pm}^{[2,9]}$; the $\mathrm{Zn}-\mathrm{N}$ bond lengths to the amido ligands show a mean value of $208.5 \mathrm{pm},{ }^{[2,9]}$ whereas values of $212.3 \mathrm{pm}$ are observed in 3. Furthermore, a strong folding of the $\mathrm{Zn}_{2} \mathrm{~N}_{2}$ ring is imposed. Whereas the folding angle in $\mathbf{2}$ is $167.1^{\circ}$, the corresponding value after $\mathrm{C}-\mathrm{C}$ bond formation lies at $109.9^{\circ}$. Because of this folding, the triisopropylsilyl substituents are pushed apart from each other and the $Z n$-bonded methyl groups move toward each other and consequently between the $i \operatorname{Pr}_{3} \mathrm{Si}$ substituents. The $\mathrm{Zn} 1-\mathrm{N} 2-\mathrm{Sil}$ angle is therefore enhanced. Furthermore, the short transannular $\mathrm{Zn} 1 \cdots \mathrm{Zn} 1^{\prime}$ contact of $272.8 \mathrm{pm}$ increases the electrostatic repulsion between the metal cations. In VI, a comparable metal-metal contact of 274.9(1) pm was found. ${ }^{[2]}$ The rearrangement of the aliphatic substituents gives rise to a slight contraction of most of the bond lengths. The $\mathrm{Zn} 1-\mathrm{C} 7$ distance is approximately $3 \mathrm{pm}$ smaller, whereas this trend is less dramatic for the Si1-N2 and $\mathrm{Si} 1-\mathrm{C}$ bonds.

Figure 4 shows the molecular structure and numbering scheme of $\mathbf{8}$. The disordered THF molecule between these dimeric magnesium bis(amides) is neglected, due to the lack of short contacts between this solvent molecule and $\mathbf{8}$. Derivative $\mathbf{8}$ represents the key compound in explaining the mechanism discussed above. The numbering scheme is similar to that shown for $\mathbf{2}$ and $\mathbf{3}$; atoms generated by crystallographic inversion symmetry are marked with apostrophes. The central feature is the $\mathrm{Mg}_{2} \mathrm{~N}_{2}$ ring with distorted tetrahedrally coordinated magnesium atoms. The $\mathrm{N} 2-\mathrm{Mg} 1-\mathrm{N} 2^{\prime}$ angle in this centrosymmetric ring has a value of $95.2^{\circ}$. The $\mathrm{Mg}-\mathrm{O}$ distances of $202.7 \mathrm{pm}$ lie in the expected region. ${ }^{[31,32]}$ Selected structural parameters are summarized in Table 1.

Special attention should be drawn to the amidomethylpyridyl fragment. The aromaticity of the pyridyl moiety is broken, and alternating long and short $\mathrm{C}-\mathrm{C}$ bonds are observed. The negative charge is located on both the nitrogen atoms, thus giving a cyclic magnesium bis(amide). The N1-C5 distance of $135.9 \mathrm{pm}$ represents a characteristic value for an $\mathrm{N}-\mathrm{C}$ single bond to an $\mathrm{sp}^{2}$-hybridized carbon atom, whereas the $\mathrm{N} 1-\mathrm{C} 1$ bond $(140.7 \mathrm{pm})$ seems to be elongated. The $\mathrm{N} 2-\mathrm{C} 6$ distance of $145.6 \mathrm{pm}$ is larger, due to the tetrahedral environment of N2 and the steric strain induced by the trialkylsilyl substituent. The $\mathrm{C}-\mathrm{C}$ bonds of the pyridyl fragment show a slight degree of conjugation, as the $\mathrm{C}-\mathrm{C}$ single bonds are shorter (mean value 142.6) 
Table 1 . Selected bond lengths $[\mathrm{pm}]$ and angles $\left[^{\circ}\right]$ of $\mathbf{2}, \mathbf{3}, \mathbf{8}, \mathbf{9}$, and $\mathbf{1 0}$

\begin{tabular}{|c|c|c|c|c|c|c|}
\hline Compound & 2 & 3 & 8 & $9^{[\mathrm{a}]}$ & $9^{[\mathrm{b}]}$ & $10^{[\mathrm{b}]}$ \\
\hline M1-N1 & $211.8(2)$ & $210.9(3)$ & 203.5(4) & $211.8(4)$ & 214.4(3) & 203.1(3) \\
\hline $\mathrm{M} 1-\mathrm{N} 2$ & $210.9(2)$ & 212.2(3) & $209.6(4)$ & $215.7(4)$ & $213.4(2)$ & $206.4(3)$ \\
\hline $\mathrm{M} 1-\mathrm{N} 2^{\prime}$ & $209.9(2)$ & 212.2(3) & $208.6(3)$ & $211.7(3)$ & $211.7(3)$ & $207.0(3)$ \\
\hline M1-C7 & $198.4(2)$ & $195.1(4)$ & $202.7(3)^{[\mathrm{c}]}$ & $213.2(5)$ & 211.9(4) & $199.3(3)^{[\mathrm{c}}$ \\
\hline M1 ‥M1' & $284.8(1)$ & $272.78(9)$ & 281.9(3) & 293.4(3) & 293.7(2) & $281.0(2)$ \\
\hline $\mathrm{N} 1-\mathrm{C} 1$ & $133.8(3)$ & $133.5(5)$ & $140.7(6)$ & $134.3(5)$ & $134.4(4)$ & $140.1(4)$ \\
\hline $\mathrm{N} 1-\mathrm{C} 5$ & $135.4(3)$ & $133.7(5)$ & $135.9(6)$ & $135.6(6)$ & $132.2(4)$ & $136.7(4)$ \\
\hline $\mathrm{C} 1-\mathrm{C} 2$ & $138.3(3)$ & $137.6(6)$ & $145.0(6)$ & $140.3(6)$ & $138.7(5)$ & $144.2(5)$ \\
\hline $\mathrm{C} 1-\mathrm{C} 6$ & $151.0(3)$ & $151.0(5)$ & $136.2(7)$ & $151.7(6)$ & $150.4(5)$ & $137.0(5)$ \\
\hline $\mathrm{C} 2-\mathrm{C} 3$ & 137.4(3) & $138.3(7)$ & $134.9(8)$ & $136.6(7)$ & $136.0(5)$ & $135.8(6)$ \\
\hline $\mathrm{C} 3-\mathrm{C} 4$ & $138.3(4)$ & $135.9(8)$ & $140.2(8)$ & $137.6(8)$ & $137.0(6)$ & $139.9(6)$ \\
\hline $\mathrm{C} 4-\mathrm{C} 5$ & $136.2(3)$ & 137.1(7) & $136.9(7)$ & $135.6(7)$ & $137.5(5)$ & $135.4(6)$ \\
\hline N2-C6 & $147.5(3)$ & $146.8(4)$ & $145.6(5)$ & $148.0(4)$ & $148.7(4)$ & $146.1(4)$ \\
\hline N2-Si1 & $174.6(2)$ & $173.8(3)$ & $174.4(3)$ & $172.7(3)$ & $173.0(2)$ & $172.3(3)$ \\
\hline $\mathrm{C} 6-\mathrm{C}^{\prime}$ & - & $159.8(6)$ & - & - & - & - \\
\hline $\mathrm{M} 1-\mathrm{N} 2-\mathrm{M} 1^{\prime}$ & $85.18(7)$ & $80.0(1)$ & $84.8(1)$ & $86.7(1)$ & $87.39(9)$ & 85.7(1) \\
\hline $\mathrm{N} 2-\mathrm{M} 1-\mathrm{N} 2^{\prime}$ & $94.14(7)$ & $76.5(1)$ & $95.2(1)$ & $93.3(1)$ & $92.61(9)$ & $94.4(1)$ \\
\hline $\mathrm{M} 1-\mathrm{N} 2-\mathrm{C} 6$ & $109.8(1)$ & $94.1(2)$ & $92.1(2)$ & $109.4(3)$ & $108.2(2)$ & $99.9(2)$ \\
\hline $\mathrm{N} 2-\mathrm{C} 6-\mathrm{C} 1$ & $115.7(2)$ & $114.0(3)$ & $123.6(5)$ & $115.2(3)$ & $114.9(3)$ & $123.3(4)$ \\
\hline $\mathrm{C} 6-\mathrm{C} 1-\mathrm{N} 1$ & $117.8(2)$ & $114.7(3)$ & $119.7(4)$ & $119.3(4)$ & $117.4(3)$ & $118.9(3)$ \\
\hline $\mathrm{C} 1-\mathrm{N} 1-\mathrm{M} 1$ & $113.4(1)$ & 107.1(2) & $104.9(3)$ & $113.3(3)$ & $112.7(2)$ & $104.9(2)$ \\
\hline $\mathrm{N} 1-\mathrm{M} 1-\mathrm{N} 2$ & $82.53(6)$ & $83.0(1)$ & $87.8(2)$ & $82.2(2)$ & 82.0(1) & $88.2(1)$ \\
\hline Si1-N2-C6 & $111.5(1)$ & $117.8(2)$ & $111.7(3)$ & $114.2(2)$ & $113.7(2)$ & $117.4(2)$ \\
\hline Si1-N2-M1 & $115.65(9)$ & $128.1(2)$ & 131.2(2) & $111.6(2)$ & $114.4(1)$ & $128.3(2)$ \\
\hline $\mathrm{Si} 1-\mathrm{N} 2-\mathrm{M} 1^{\prime}$ & $120.48(9)$ & $122.3(2)$ & $128.4(2)$ & $124.3(2)$ & $122.5(1)$ & $123.8(1)$ \\
\hline
\end{tabular}

${ }^{[\mathrm{a}]}$ Data from the solid state structure of 9. ${ }^{[\mathrm{b}]}$ Parameters from the crystal structure of 9・10. ${ }^{[\mathrm{c}]} \mathrm{Mg} 1-\mathrm{O} 01$.

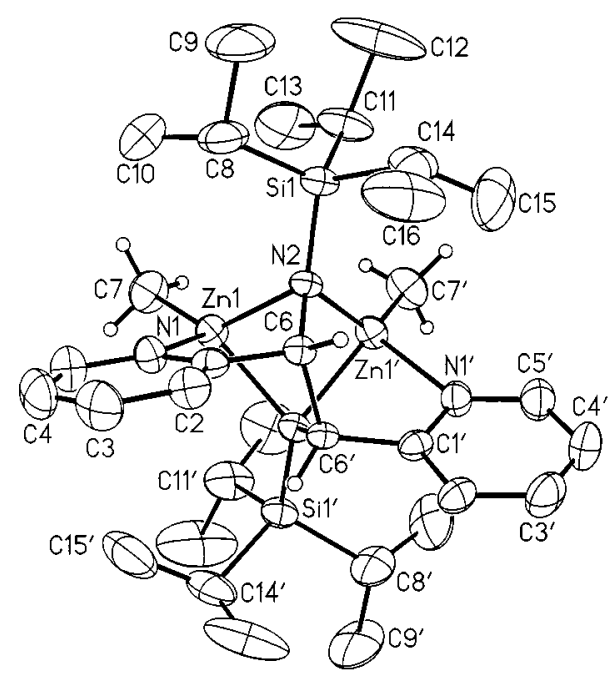

Figure 3. Molecular structure of 3; the ellipsoids represent $40 \%$ probability; atoms generated by the crystallographic $C_{2}$ symmetry $(-x+2, y,-z+0.5)$ are marked with apostrophes; the hydrogen atoms are omitted for clarity, with the exception of those at C6/C6'

than expected (reference value $1.48 \mathrm{pm}^{[33]}$ ) whereas the $\mathrm{C}=$ $\mathrm{C}$ double bonds (mean value $136.0 \mathrm{pm}$ ) are widened (reference value $1.34 \mathrm{pm}^{[33]}$ ).

The Mg1-N1 bond length of $203.5 \mathrm{pm}$ is rather short, due to the low coordination number of N1 and the electrostatic attraction between the nitrogen atom and the metal center. The distorted tetrahedral surrounding and the steric shielding of $\mathrm{N} 2$ produce a longer $\mathrm{N} 2-\mathrm{Mg} 1$ bond length. The transannular $\mathrm{Mg} 1 \cdots \mathrm{Mg} 1^{\prime}$ contact of $281.9 \mathrm{pm}$ is rather

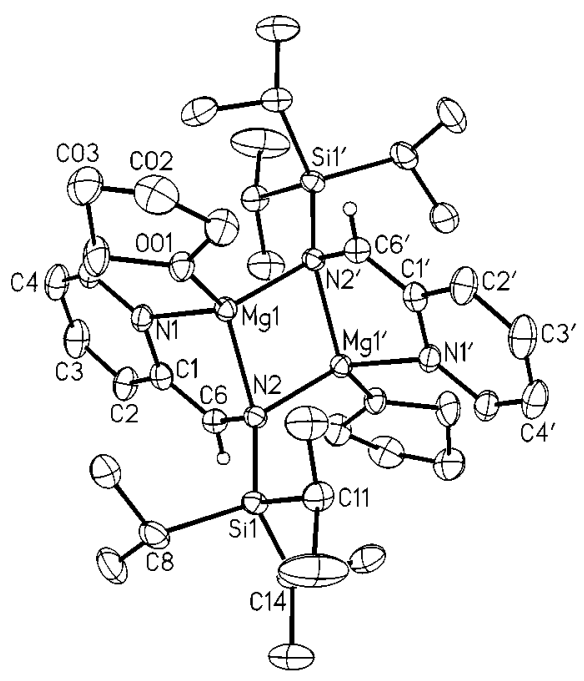

Figure 4. Molecular structure of $\mathbf{8}$; the ellipsoids represent $40 \%$ probability; atoms generated by the crystallographic inversion symmetry $(-x,-y+1,-z+2)$ are marked with apostrophes; the hydrogen atoms are omitted for clarity, with the exception of those at $\mathrm{C} 6 / \mathrm{C}^{\prime}$

short, however, this is a consequence of the small endocyclic $\mathrm{Mg}-\mathrm{N}$ bonds lengths.

Figure 5 represents the molecular structure and numbering scheme of dimeric 9. This molecule shows point symmetry and so structure type $\mathbf{D}$ is achieved. Atoms generated by the inversion symmetry are marked with apostrophes. In comparison with the isotypic zinc complex II and with 2, the metal-carbon bonds of 9 are elongated by approxim- 
ately $15 \mathrm{pm}$ in accordance to the van der Waals radii difference $\left(r_{\mathrm{Mg}}=170 \mathrm{pm} ; r_{\mathrm{Zn}}=140 \mathrm{pm}^{[34]}\right)$; however, the difference between the $\mathrm{Mg}-\mathrm{N}$ and $\mathrm{Zn}-\mathrm{N}$ bond lengths is far less distinct. Because of the slightly larger metal centers, the

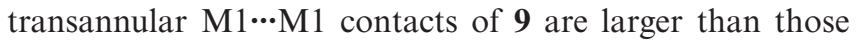
in the similar zinc derivatives II and $\mathbf{2}$. This is achieved by widening of the $\mathrm{Mg} 1-\mathrm{N} 2-\mathrm{Mg} 1$ ' bond angle compared with the corresponding values in the zinc complexes.

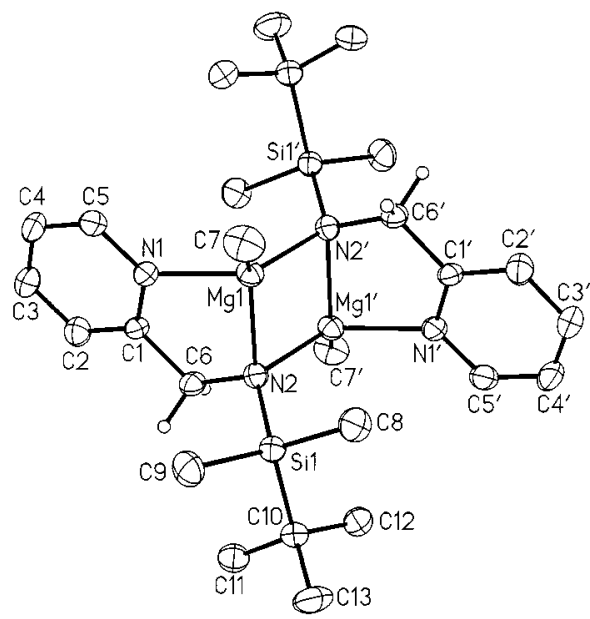

Figure 5. Molecular structure of 9; the ellipsoids represent $40 \%$ probability; atoms generated by the crystallographic inversion symmetry $(-x+1,-y+1,-z)$ are marked with apostrophes; the hydrogen atoms are omitted for clarity, with the exception of those at $\mathrm{C} 6 / \mathrm{Cb}^{\prime}$

Figure 6 represents the molecular structure and numbering scheme of $\mathbf{1 0}$. This molecule cocrystallizes in an equimolar ratio with 9 as shown in Figure 7. The solid-state structure can be regarded as a layer structure, with the molecules of $\mathbf{9}$ in $(h, k, 0)$ and those of $\mathbf{1 0}$ in $(h, k, 0.5)$. Both these molecules show inversion symmetry and a nearly similar arrangement of their substituents. The magnesium atoms are in a distorted tetrahedral environment. The molecular structure of 9 is similar to the structure described above and no detailed discussion is necessary. However, $\mathbf{1 0}$ shows some remarkable structural features. The center of interest concerns the disturbed aromaticity of the pyridyl fragment, which is similar to that in $\mathbf{8}$. Detailed discussion therefore seems unnecessary.

Mononuclear 1,2-dipyridyl-1,2-bis(trialkylsilylamido)ethane complexes of tin(II) preferentially form as $(R, R)$ and $(S, S)$ isomers; however, a minor quantity of the meso form is also produced from this reaction. This situation allows these isomers to be compared in the crystalline state, and so the numbering schemes are alike for all these derivatives. Figures 8 to 10 show the molecular structures and numbering schemes of $\mathbf{1 2}, \mathbf{1 2}^{\prime}$, and $\mathbf{1 4}$, respectively; Table 2 contains selected structural data. The backbone consists of the stereogenic centers $\mathrm{C} 1$ and $\mathrm{C} 2$. The $\mathrm{Sn}$-bonded pyridyl fragment is located at $\mathrm{C} 1$, whereas the uncoordinated pyridyl substituent is bonded to $\mathrm{C} 2$. The tin atoms are in a trigonalpyramidal environment formed by the three nitrogen atoms $\mathrm{N} 1, \mathrm{~N} 2$, and N21, whereas N22 shows no short contacts to any tin(II) centers. The $\mathrm{Sn}-\mathrm{N} 21$ bond lengths are nearly 20

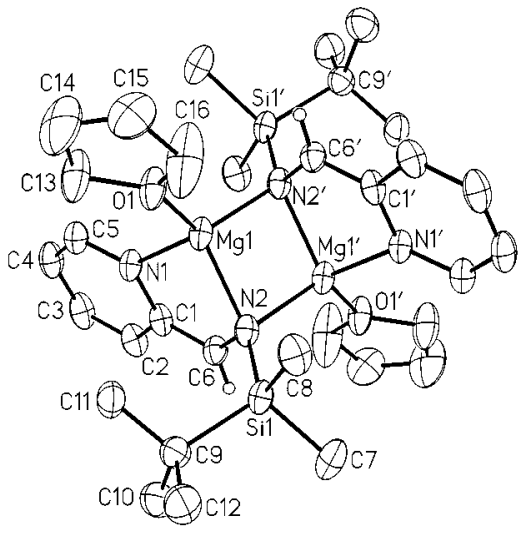

Figure 6. Molecular structure of 10; the ellipsoids represent 30\% probability; atoms generated by the crystallographic inversion symmetry $(-x+2,-y+2,-z+1)$ are marked with apostrophes; the hydrogen atoms are omitted for clarity, with the exception of those at $\mathrm{C} 6 / \mathrm{C} 6$

pm larger than the tin-nitrogen distances to the negatively charged atoms N1 and N2. The sterically less demanding tert-butyldimethylsilyl substituent allows shorter $\mathrm{Sn}-\mathrm{N}$ bonds than the $N$-bonded triisopropylsilyl group. A remarkable difference concerns the newly formed $\mathrm{C} 1-\mathrm{C} 2$ bond. Whereas this bond is extremely long in compounds $\mathbf{1 2}$ and $\mathbf{1 2}$, a characteristic value of 153.5(6) is found in $\mathbf{1 4}$. However, the ring strain in $\mathbf{1 4}$ gives rise to an elongated $\mathrm{C} 1-\mathrm{C} 11$ bond. A comparison of the structural parameters of $\mathbf{1 2}\left[(R, R)\right.$ and $(S, S)$ isomers] and $\mathbf{1 2}^{\prime}$ (meso isomer) show two main differences, namely the smaller $\mathrm{Sn}-\mathrm{N} 21$ bond length and the smaller $\mathrm{Sn}-\mathrm{N} 2-\mathrm{Si} 2$ bond angle in $\mathbf{1 2}^{\prime}$. Both these observations can be attributed to reduced intramolecular steric strain in this isomer.

The stereochemically active lone pair at tin(II) gives rise to the pyramidal coordination sphere at the metal center. Similar observations are already well known for other tin(II) amides. The $\mathrm{Sn}-\mathrm{N} 1$ and $\mathrm{Sn}-\mathrm{N} 2$ bond lengths are comparable to those published for $\mathrm{Sn}\left[\mathrm{N}\left(\mathrm{SiMe}_{3}\right)_{2}\right]_{2} \cdot{ }^{[3-37]} \mathrm{A}$ higher coordination number of three ${ }^{[38]}$ or four ${ }^{[39]}$ at the tin(II) center results in longer $\mathrm{Sn}-\mathrm{N}$ bonds.

In 14, the nitrogen atoms $\mathrm{N} 1$ and $\mathrm{N} 2$ are in a planar environment (angle sums of $\mathrm{N} 1$ and N2: 359.3 and $359.7^{\circ}$ ). The larger trialkylsilyl substituents produce distortions and smaller angle sums at the amide moieties (12: N1 354.4 $\mathrm{N} 2358.1^{\circ} ; \mathbf{1 2}^{\prime}$ : N1 $357.8^{\circ}, \mathrm{N} 2350.2^{\circ}$ ).

\section{NMR Spectroscopy}

NMR spectroscopic data for the zinc- and magnesiumcontaining molecules are summarized in Table 3; the numbering scheme is given in Scheme 11. The influence of the trialkylsilyl substituents on the chemical shifts of the pyridylmethyl fragments is very small. The compound classes are therefore distinguishable by the $\delta$ values of the methylene moieties in the proton NMR experiments: the (2-pyridylmethyl)(trialkylsilyl)amines $1\left(\mathrm{R}=\mathrm{Si}_{i} \operatorname{Pr}_{3}\right)$ and $\mathbf{I}(\mathrm{R}=\mathrm{Si}$ $\mathrm{Me}_{2} t \mathrm{Bu}$ ) show their resonances at $\delta=4$.1. Substitution of the $\mathrm{H}$ atom by a methylmetal fragment ( 2 and II: $\mathrm{Zn} ; \mathbf{7}$ and 9: $\mathrm{Mg}$ ) produces a low-field shift of approximately $0.6 \mathrm{ppm}$, 

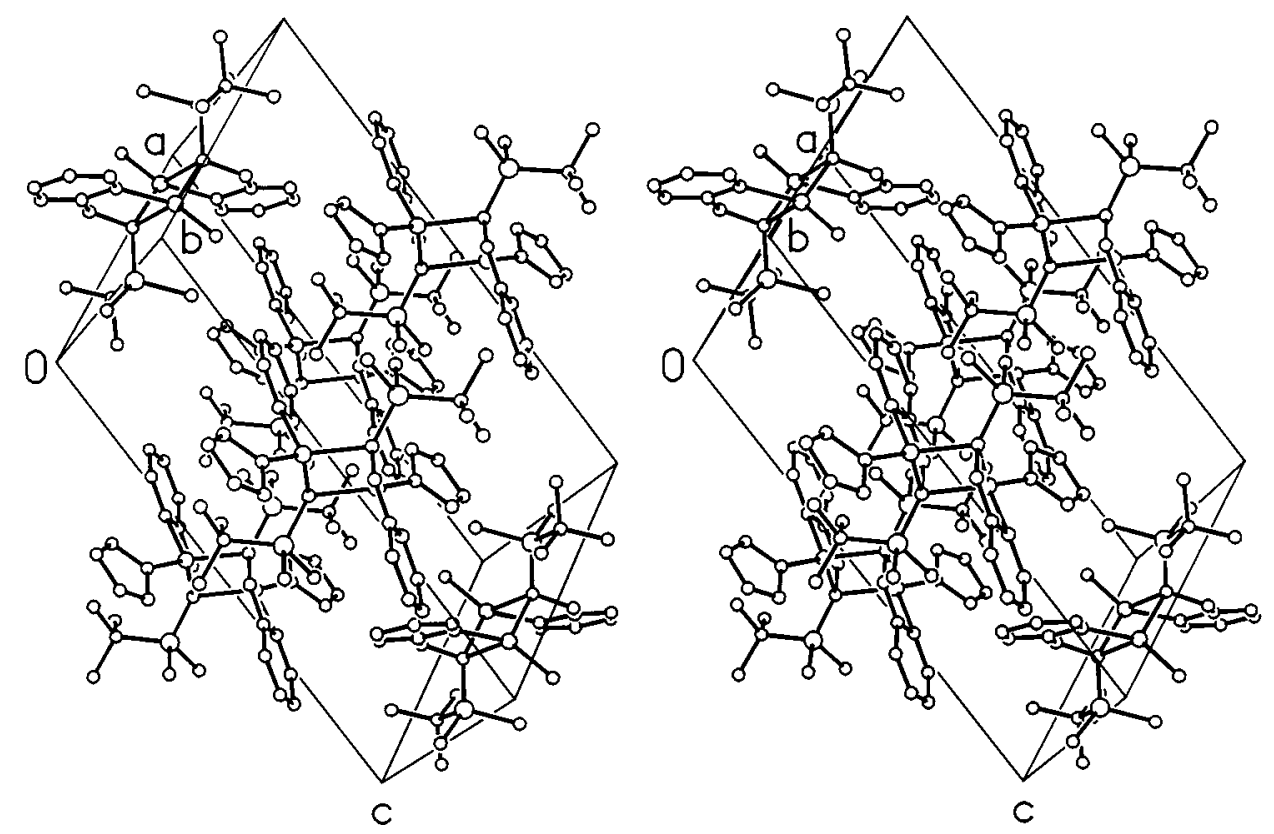

Figure 7. Representation of the arrangement of the molecules of $\mathbf{9 \cdot 1 0}$ in the unit cell; the atoms are shown with arbitrary radii (see text)

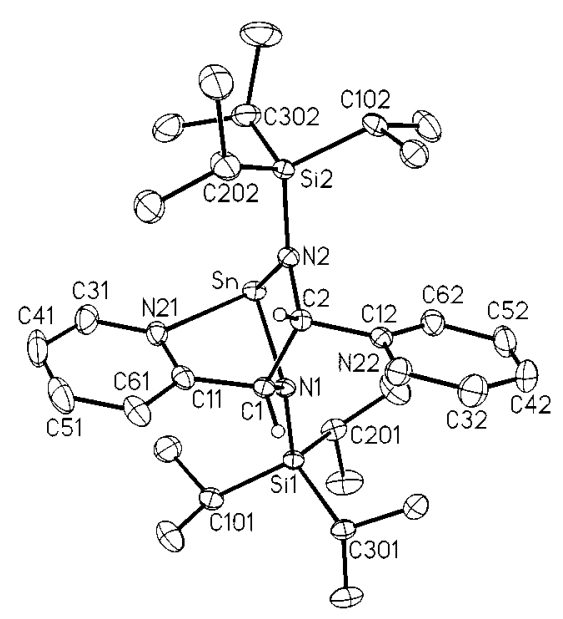

Figure 8. Molecular structure of 12; the ellipsoids represent $40 \%$ probability; the hydrogen atoms are omitted for clarity, with the exception of those at $\mathrm{C} 1$ and $\mathrm{C} 2$

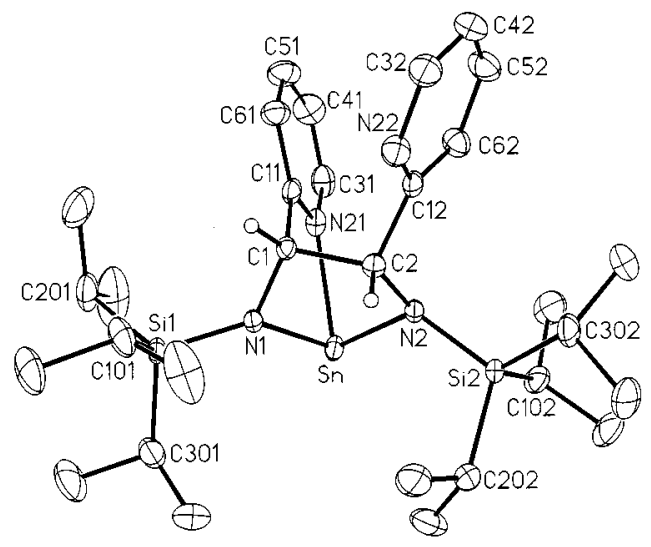

Figure 9. Molecular structure of 12' (meso form); the ellipsoids represent $40 \%$ probability; the hydrogen atoms are omitted for clarity, with the exception of those at $\mathrm{C} 1$ and $\mathrm{C} 2$

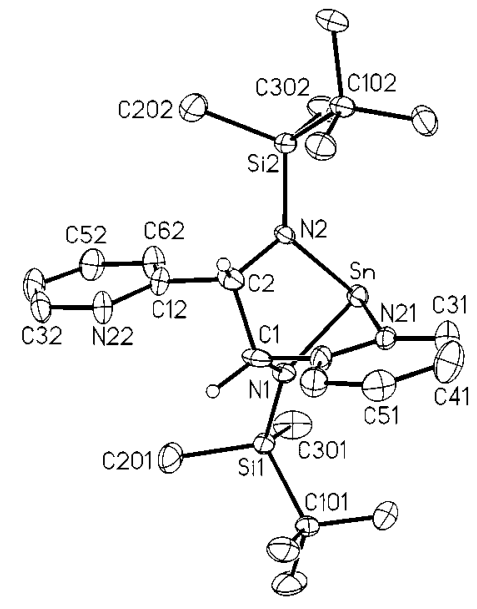

Figure 10. Molecular structure of 14; the ellipsoids represent $40 \%$ probability; the hydrogen atoms are omitted for clarity, with the exception of those at $\mathrm{C} 1$ and $\mathrm{C} 2$

whereas the $\mathrm{C}-\mathrm{C}$-coupled derivatives $\mathbf{3}$ and III give chemical shifts of $\delta=4.0$. The resonances of these methylene moieties in metal bis[(2-pyridylmethyl)(trialkylsilyl)amide] (Zn: $\mathbf{4}$ and IV; Mg: 6) appear at a rather low field at $\delta=4.9$. Similar tendencies are deducible from the ${ }^{13} \mathrm{C}\left\{{ }^{1} \mathrm{H}\right\}$ NMR experiments; the amines $\mathbf{1}$ and $\mathbf{I}$ have values of $\delta=48$, whereas the metalated amines show low-field shifts of approximately $6 \mathrm{ppm}$ regardless of the metal $(\mathrm{Zn}$ or $\mathrm{Mg})$. The $\mathrm{C}-\mathrm{C}$ coupling gives chemical shifts of approximately $\delta=$ 67 for these carbon atoms. In the NMR spectroscopic experiments, the influences both of the steric demand of the trialkylsilyl substituents and of the nature of the metal center $(\mathrm{Zn}$ or $\mathrm{Mg})$ seem to play a minor role regarding the NMR spectroscopic data of the pyridylmethyl groups. The dependence on the solvent was elucidated for compound $\mathbf{9}$; the influence of the solvent on the NMR spectroscopic data 
Table 2. Selected bond lengths $[\mathrm{pm}]$ and angles $\left[{ }^{\circ}\right]$ of $\mathbf{1 2}, \mathbf{1 2}^{\prime}$, and $\mathbf{1 4}$

\begin{tabular}{|c|c|c|c|}
\hline Compound & $12^{[\mathrm{a}]}$ & $12^{\prime}[\mathrm{b}]$ & $14^{[\mathrm{a}]}$ \\
\hline $\mathrm{Sn}-\mathrm{N} 1$ & 209.2(2) & $209.9(3)$ & $207.5(3)$ \\
\hline $\mathrm{Sn}-\mathrm{N} 2$ & $210.7(2)$ & 213.1(3) & $209.6(3)$ \\
\hline $\mathrm{Sn}-\mathrm{N} 21$ & $238.8(2)$ & $231.8(3)$ & $238.3(3)$ \\
\hline N1-Sil & $172.2(2)$ & $172.4(3)$ & $170.8(3)$ \\
\hline $\mathrm{N} 2-\mathrm{Si} 2$ & $172.9(2)$ & 173.3(3) & $170.9(3)$ \\
\hline $\mathrm{C} 1-\mathrm{C} 2$ & 157.1(3) & $159.3(4)$ & $153.5(6)$ \\
\hline $\mathrm{C} 1-\mathrm{N} 1$ & $145.4(3)$ & $145.7(4)$ & $144.9(5)$ \\
\hline $\mathrm{C} 2-\mathrm{N} 2$ & $146.2(3)$ & $146.7(4)$ & $145.1(5)$ \\
\hline $\mathrm{C} 1-\mathrm{C} 11$ & $151.8(3)$ & $150.6(5)$ & $157.6(6)$ \\
\hline $\mathrm{C} 11-\mathrm{N} 21$ & 134.1(3) & $133.8(5)$ & $133.4(5)$ \\
\hline N21-C31 & $134.9(3)$ & $133.9(5)$ & $132.3(6)$ \\
\hline $\mathrm{C} 31-\mathrm{C} 41$ & $136.8(5)$ & 137.1(6) & $137.8(7)$ \\
\hline $\mathrm{C} 41-\mathrm{C} 51$ & $137.0(5)$ & $138.5(6)$ & $136.6(7)$ \\
\hline C51-C61 & $138.8(4)$ & $137.8(6)$ & $135.9(6)$ \\
\hline C11-C61 & 139.1(4) & $138.5(5)$ & $137.3(6)$ \\
\hline $\mathrm{C} 2-\mathrm{C} 12$ & $151.7(3)$ & $152.1(5)$ & $154.0(6)$ \\
\hline $\mathrm{C} 12-\mathrm{N} 22$ & 134.1(3) & $133.1(4)$ & $135.1(5)$ \\
\hline $\mathrm{N} 22-\mathrm{C} 32$ & $134.4(4)$ & $134.3(5)$ & $131.3(5)$ \\
\hline C $32-C 42$ & $136.2(5)$ & $137.3(6)$ & $136.3(7)$ \\
\hline $\mathrm{C} 42-\mathrm{C} 52$ & $137.3(5)$ & $137.7(6)$ & $137.7(7)$ \\
\hline C52-C62 & $138.4(4)$ & $137.3(6)$ & $135.2(6)$ \\
\hline $\mathrm{C} 12-\mathrm{C} 62$ & $137.7(4)$ & $138.8(5)$ & $138.5(6)$ \\
\hline $\mathrm{N} 1-\mathrm{Sn}-\mathrm{N} 2$ & $82.45(7)$ & $82.2(1)$ & 81.4(1) \\
\hline $\mathrm{N} 1-\mathrm{Sn}-\mathrm{N} 21$ & $74.35(7)$ & $75.4(1)$ & $75.3(1)$ \\
\hline $\mathrm{N} 2-\mathrm{Sn}-\mathrm{N} 21$ & $81.45(7)$ & $82.5(1)$ & $81.2(1)$ \\
\hline $\mathrm{C} 1-\mathrm{N} 1-\mathrm{Sn}$ & 101.8(1) & 101.1(2) & $102.6(2)$ \\
\hline $\mathrm{C} 1-\mathrm{N} 1-\mathrm{Si} 1$ & $124.4(1)$ & $123.4(2)$ & $124.9(2)$ \\
\hline Sil-N1-Sn & $128.2(1)$ & 133.3(2) & $131.8(2)$ \\
\hline $\mathrm{C} 2-\mathrm{N} 2-\mathrm{Sn}$ & $109.8(1)$ & $109.4(2)$ & $110.9(2)$ \\
\hline $\mathrm{C} 2-\mathrm{N} 2-\mathrm{Si} 2$ & $120.9(2)$ & $123.6(2)$ & $120.9(2)$ \\
\hline $\mathrm{Si} 2-\mathrm{N} 2-\mathrm{Sn}$ & $127.4(1)$ & $117.2(1)$ & $127.9(2)$ \\
\hline
\end{tabular}

[a] Data for the racemate composed of the $(R, R)$ and $(S, S)$ isomers. [b] Parameters for the $(R, S)$ isomer (meso form).

is of the same magnitude as that of the substitution pattern.

The NMR parameters of the tin(II) complexes are summarized in Table 4. All these complexes are mononuclear, and variations in the NMR spectroscopic data are therefore to be expected. The solid-state structures of $\mathbf{1 2}$ and $\mathbf{1 4}$ show that only one pyridyl group bonds to the tin center, whereas the other one shows no short contacts to a metal atom. In solution, both pyridyl fragments are chemically and magnetically equivalent; the exchange process is fast on the NMR timescale even at low temperatures. In general, the $\delta$ values of the methylene fragments are shifted towards lower field, relative to the zinc and magnesium derivatives, in the proton and ${ }^{13} \mathrm{C}\left\{{ }^{1} \mathrm{H}\right\}$ NMR experiments. The ${ }^{119} \mathrm{Sn}\left\{{ }^{1} \mathrm{H}\right\}$

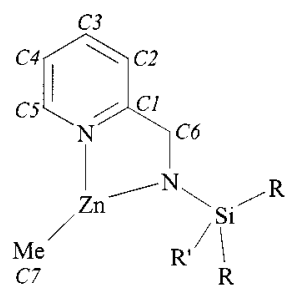

Scheme 11. Numbering scheme of the (2-pyridylmethyl)(trialkylsilyl)amide ligand for the assignment of the NMR spectroscopic data chemical shifts were found in the characteristic region for triply coordinated tin(II) compounds. ${ }^{[40-42]}$

The ${ }^{1} \mathrm{H}$ NMR spectroscopic data for $\mathbf{1 5}$ and $\mathbf{1 6}^{[22]}$ are summarized in Table 5; the corresponding values for (benzyl)(trialkylsilyl)amine $(\mathbf{V})^{[21]}$ are also included for comparison. The low-field shift of the methylene moiety of 16 compared to $\mathbf{1 5}$ is contrary to the observations concerning the pyridyl compounds $\mathbf{2}$ and $\mathbf{4}$ as well as II and IV, respectively, where the ${ }^{1} \mathrm{H}$ NMR spectra show the $\mathrm{CH}_{2}$ signals of the heteroleptic derivatives $\mathbf{2}$ and II at a higher field.

\section{Conclusion}

The zinc-mediated $\mathrm{C}-\mathrm{C}$ coupling reaction is not dependent on the intramolecular steric strain introduced by the trialkylsilyl substituents. However, the use of the triisopropylsilyl ligand permitted the crystallographic characterization of the cyclic magnesium bis(amide) $\mathbf{8}$, which is thought to be the intermediate in this reaction. The intermediate with the smaller tert-butyldimethylsilyl substituent cocrystallized with 9, and its fast decomposition was prevented due to its removal from the reaction mixture. Furthermore, the solid-state structures of $\mathbf{2}$ and II vary with the steric demand of the trialkylsilyl group but the reactivity is all but retained. As one would expect, this coupling reaction is strongly dependent on the redox potential of the metal employed in this reaction. The pyridyl substituent is necessary to support the $\mathrm{C}-\mathrm{C}$ coupling reaction. The key step of the mechanism is the metalation of the methylene group and a charge migration to the pyridyl nitrogen atom, thus forming a cyclic bis(amide). Because of the $\mathrm{C}-\mathrm{C}$ coupling, the aromaticity of the pyridyl group is regained; this may be the driving force for this step. This also provides an explanation of why no similar molecule is observed in the zinc-mediated reaction: the elevated reaction temperature prevents the reaction from stopping at this step, since the reduction of the metal is too easy.

The zinc-mediated $\mathrm{C}-\mathrm{C}$ coupling reaction results in the formation of the $(R, R)$ - and $(S, S)$-isomeric 1,2-dipyridyl1,2-bis(trialkylsilylamido)ethane ligand. The meso form is not observed in the course of this reaction. However, the tin-mediated $\mathrm{C}-\mathrm{C}$ coupling yields a mixture of all possible isomers, although the demanding trialkylsilyl groups favor the $(R, R)$ and $(S, S)$ forms. Whereas the zinc- and magnesium-containing complexes crystallize as dimers, the mononuclear tin compounds are monomeric in the solid state and in solution.

This zinc-mediated $\mathrm{C}-\mathrm{C}$ coupling reaction is novel in zinc chemistry. However, it allows the quantitative synthesis of a dinuclear zinc complex with the metal atoms in close contact with one another, due to the folding of the $\mathrm{Zn}_{2} \mathrm{~N}_{2}$ ring. Further investigations will now concentrate on the influence of the trialkylsilyl substituents on the properties of these compounds and comparison with the tert-butyl-substituted derivatives described earlier by van Koten and coworkers. $^{[2,9]}$ 
Table 3. NMR spectroscopic data of $\mathbf{1 - 7}$ and 9; data for $\mathbf{I}-\mathbf{I V}$ are also given for comparison

\begin{tabular}{|c|c|c|c|c|c|c|c|}
\hline $\begin{array}{l}\text { Compound } \\
\text { Solvent }\end{array}$ & $\begin{array}{c}1 \\
\mathrm{C}_{6} \mathrm{D}_{6}\end{array}$ & $\begin{array}{c}\mathbf{2} \\
\mathrm{C}_{6} \mathrm{D}_{6}\end{array}$ & $\begin{array}{c}3 \\
\mathrm{C}_{6} \mathrm{D}_{6}\end{array}$ & $\begin{array}{c}4 \\
\mathrm{C}_{6} \mathrm{D}_{6}\end{array}$ & $\begin{array}{c}\mathbf{5 a} \\
{\left[\mathrm{D}_{8}\right] \mathrm{THF}}\end{array}$ & $\begin{array}{c}\mathbf{5 b} \\
{\left[\mathrm{D}_{8}\right] \mathrm{THF}}\end{array}$ & $\stackrel{6}{\mathrm{C}_{6} \mathrm{D}_{6}}$ \\
\hline \multicolumn{8}{|l|}{${ }^{1} \mathrm{H}$} \\
\hline$\delta(\mathrm{H} 2)$ & 7.09 & 6.54 & 6.78 & 6.65 & 7.30 & 7.05 & 6.75 \\
\hline$\delta(\mathrm{H} 3)$ & 7.15 & 6.79 & 6.95 & 6.83 & 7.68 & 7.52 & 6.96 \\
\hline$\delta(\mathrm{H} 4)$ & 6.66 & 6.34 & 6.50 & 6.36 & 7.20 & 7.14 & 6.46 \\
\hline$\delta(\mathrm{H} 5)$ & 8.48 & 7.75 & 8.06 & 7.91 & 8.44 & 8.41 & 7.91 \\
\hline$\delta(\mathrm{H} 6)$ & $4.14^{[\mathrm{a}]}$ & 4.67 & 4.06 & $4.94^{[\mathrm{b}]}$ & 4.19 & 4.17 & $4.85^{[\mathrm{c}]}$ \\
\hline$\delta(\mathrm{H} 7)$ & - & -0.13 & 0.21 & - & - & - & - \\
\hline$\delta\left(\mathrm{CHMe}_{2}\right)$ & 1.05 & 1.35 & 1.00 & 1.41 & 1.05 & 1.07 & 0.88 \\
\hline$\delta\left(\mathrm{CH} M e_{2}\right)$ & 1.06 & 1.33 & 0.91 & 1.36 & 1.05 & 1.07 & 0.88 \\
\hline$\delta(\mathrm{SiMe})$ & - & - & - & - & - & - & - \\
\hline$\delta(\mathrm{SiMe})$ & - & - & - & - & - & - & - \\
\hline$\delta(\mathrm{Si} t \mathrm{Bu})$ & - & - & - & - & - & - & - \\
\hline$\delta(\mathrm{NH})$ & 1.28 & - & - & - & n.o. ${ }^{[\mathrm{d}]}$ & n.o. ${ }^{[\mathrm{d}]}$ & - \\
\hline \multicolumn{8}{|l|}{${ }^{13} \mathrm{C}\left\{{ }^{1} \mathrm{H}\right\}$} \\
\hline$\delta(\mathrm{C} 1)$ & 163.0 & 166.4 & 168.7 & 166.2 & 158.4 & 157.8 & 169.9 \\
\hline$\delta(\mathrm{C} 2)$ & 120.4 & 121.1 & 119.8 & 121.1 & 122.4 & 122.3 & 120.6 \\
\hline$\delta(\mathrm{C} 3)$ & 135.6 & 136.7 & 138.3 & 136.6 & 139.6 & 139.6 & 136.7 \\
\hline$\delta(\mathrm{C} 4)$ & 121.0 & 121.6 & 122.3 & 121.7 & 123.8 & 123.8 & 122.1 \\
\hline$\delta(\mathrm{C} 5)$ & 149.0 & 145.4 & 146.7 & 145.5 & 147.4 & 147.3 & 145.9 \\
\hline$\delta(\mathrm{C} 6)$ & 48.4 & 54.4 & 67.0 & 54.2 & 47.2 & 47.3 & 53.6 \\
\hline$\delta(\mathrm{C} 7)$ & - & -14.7 & -11.5 & - & - & - & - \\
\hline$\delta(\mathrm{SiCH})$ & 11.9 & 13.6 & 14.3 & 14.2 & 11.9 & 12.0 & 13.7 \\
\hline$\delta\left(\mathrm{CHM} e_{2}\right)$ & 18.4 & 19.1 & 18.9 & 18.4 & 18.1 & 18.3 & 19.6 \\
\hline$\delta(\mathrm{SiMe})$ & - & - & - & - & - & - & - \\
\hline$\delta(\mathrm{SiMe})$ & - & - & - & - & - & - & - \\
\hline$\delta\left(\mathrm{SiCMe}_{3}\right)$ & - & - & - & - & - & - & - \\
\hline$\delta\left(\mathrm{SiCMe}_{3}\right)$ & - & - & - & - & - & - & - \\
\hline \multicolumn{8}{|l|}{${ }^{29} \mathrm{Si}\left\{{ }^{1} \mathrm{H}\right\}$} \\
\hline$\delta(\mathrm{Si})$ & 6.04 & 4.09 & 6.66 & 2.49 & n.o. ${ }^{[\mathrm{d}]}$ & n.o. ${ }^{[\mathrm{d}]}$ & 0.58 \\
\hline Compound & 7 & I & II & III & IV & 9 & 9 \\
\hline Solvent & $\mathrm{C}_{6} \mathrm{D}_{6}$ & $\mathrm{C}_{6} \mathrm{D}_{6}$ & $\mathrm{C}_{6} \mathrm{D}_{6}$ & $\mathrm{C}_{6} \mathrm{D}_{6}$ & $\mathrm{C}_{6} \mathrm{D}_{6}$ & $\mathrm{C}_{6} \mathrm{D}_{6}$ & $\mathrm{THF} / \mathrm{C}_{6} \mathrm{D}_{6}$ \\
\hline \multicolumn{8}{|l|}{${ }^{1} \mathrm{H}$} \\
\hline$\delta(\mathrm{H} 2)$ & 7.36 & 7.06 & 6.52 & 6.77 & 6.64 & 6.58 & 6.65 \\
\hline$\delta(\mathrm{H} 3)$ & 7.77 & 7.17 & 6.85 & 6.97 & 6.84 & 6.92 & 6.83 \\
\hline$\delta(\mathrm{H} 4)$ & 7.19 & 6.68 & 6.47 & 6.48 & 6.38 & 6.51 & 6.37 \\
\hline$\delta(\mathrm{H} 5)$ & 8.14 & 8.47 & 8.25 & 7.98 & 7.95 & 8.28 & 7.91 \\
\hline$\delta(\mathrm{H} 6)$ & 4.80 & 4.09 & 4.65 & 4.03 & $4.93^{[\mathrm{e}]}$ & $4.70^{[\mathrm{f}]}$ & 4.95 \\
\hline$\delta(\mathrm{H} 7)$ & -1.21 & - & -0.25 & -0.51 & - & -0.72 & n.o. \\
\hline$\delta\left(\mathrm{CHMe}_{2}\right)$ & & - & - & - & - & - & - \\
\hline$\delta\left(\mathrm{CH} M e_{2}\right)$ & & - & - & - & - & - & - \\
\hline$\delta(\mathrm{SiMe})$ & - & 0.01 & -0.11 & 0.40 & 0.34 & -0.12 & 0.29 \\
\hline$\delta(\mathrm{SiMe})$ & - & 0.01 & -0.11 & 0.15 & 0.28 & -0.15 & 0.29 \\
\hline$\delta(\mathrm{Si} t \mathrm{Bu})$ & - & 0.87 & 1.10 & 0.82 & 1.27 & 1.07 & 1.27 \\
\hline$\delta(\mathrm{NH})$ & - & 1.32 & - & - & - & - & - \\
\hline \multicolumn{8}{|l|}{${ }^{13} \mathrm{C}\left\{{ }^{1} \mathrm{H}\right\}$} \\
\hline$\delta(\mathrm{C} 1)$ & 169.6 & 163.2 & 165.5 & 168.5 & 166.4 & 167.0 & 170.1 \\
\hline$\delta(\mathrm{C} 2)$ & 121.4 & 120.5 & 121.5 & 119.9 & 121.1 & 121.9 & 120.8 \\
\hline$\delta(\mathrm{C} 3)$ & 137.7 & 135.7 & 137.5 & 138.4 & 136.2 & 138.3 & 136.8 \\
\hline$\delta(\mathrm{C} 4)$ & 122.4 & 121.0 & 121.7 & 122.4 & 122.0 & 122.1 & 122.4 \\
\hline$\delta(\mathrm{C} 5)$ & 146.2 & 148.9 & 145.4 & 146.7 & 145.6 & 146.9 & 146.1 \\
\hline$\delta(\mathrm{C} 6)$ & 53.3 & 48.2 & 54.1 & 67.3 & 54.4 & 51.0 & 54.1 \\
\hline$\delta(\mathrm{C} 7)$ & -11.9 & - & -12.6 & -14.1 & - & -15.2 & -3.6 \\
\hline$\delta(\mathrm{SiCH})$ & 13.5 & - & - & - & - & - & - \\
\hline$\delta(\mathrm{CHMe})$ & 19.2 & - & - & - & - & - & - \\
\hline$\delta(\mathrm{SiMe})$ & - & -5.0 & -3.6 & -2.1 & -3.0 & -3.1 & 1.2 \\
\hline$\delta(\mathrm{SiMe})$ & - & -5.0 & -3.6 & -3.2 & -3.3 & -4.4 & 1.2 \\
\hline$\delta\left(\mathrm{SiCMe}_{3}\right)$ & - & 18.5 & 20.8 & 20.6 & 20.8 & 20.7 & 20.8 \\
\hline$\delta\left(\mathrm{SiCMe}_{3}\right)$ & - & 26.3 & 28.6 & 27.7 & 28.1 & 28.2 & 28.1 \\
\hline \multicolumn{8}{|l|}{${ }^{29} \mathrm{Si}\left\{{ }^{1} \mathrm{H}\right\}$} \\
\hline$\delta(\mathrm{Si})$ & 8.59 & 9.04 & 10.32 & 8.66 & 3.92 & 7.75 & 0.65 \\
\hline Ref. & & {$[1]$} & {$[1]$} & {$[1]$} & [1] & & \\
\hline
\end{tabular}

${ }^{[a]}$ Doublet due to coupling with NH group, ${ }^{3} J_{\mathrm{H}, \mathrm{H}}=7.6 \mathrm{~Hz} .{ }^{[\mathrm{b}]}$ Mean value of an AB spin system, $\delta_{\mathrm{A}}=4.90, \delta_{\mathrm{B}}=4.98,{ }^{2} J_{\mathrm{H}, \mathrm{H}}=19.6 \mathrm{~Hz}$. ${ }^{[\mathrm{c}]}$ Mean value of an $\mathrm{AB}$ spin system, $\delta_{\mathrm{A}}=4.81, \delta_{\mathrm{B}}=4.89,{ }^{2} J_{\mathrm{H}, \mathrm{H}}=21.0 \mathrm{~Hz}$. ${ }^{[\mathrm{d}]}$ Not observed (n.o.). ${ }^{[\mathrm{e}]}$ Mean value of an $\mathrm{AB}$ spin system, $\delta_{\mathrm{A}}=4.91, \delta_{\mathrm{B}}=4.95,{ }^{2} J_{\mathrm{H}, \mathrm{H}}=19.9 \mathrm{~Hz} \cdot{ }^{[\mathrm{f}]}$ Mean value of an $\mathrm{AB}$ spin system, $\delta_{\mathrm{A}}=4.42, \delta_{\mathrm{B}}=4.98,{ }^{2} J_{\mathrm{H}, \mathrm{H}}=19.4 \mathrm{~Hz}$. 
Table 4. NMR parameters of 11-14

\begin{tabular}{|c|c|c|c|c|}
\hline $\begin{array}{l}\text { Compound } \\
\text { Solvent }\end{array}$ & $\stackrel{11}{\text { toluene } / \mathrm{C}_{6} \mathrm{D}_{6}}$ & $\begin{array}{c}12 \\
{\left[\mathrm{D}_{8}\right] \mathrm{THF}}\end{array}$ & $\stackrel{13}{\text { toluene } / \mathrm{C}_{6} \mathrm{D}_{6}}$ & $\begin{array}{c}14 \\
{\left[\mathrm{D}_{8}\right] \mathrm{THF}}\end{array}$ \\
\hline \multicolumn{5}{|l|}{${ }^{1} \mathrm{H}$} \\
\hline$\delta(\mathrm{H} 2)$ & 6.61 & 7.77 & 6.53 & 7.69 \\
\hline$\delta(\mathrm{H} 3)$ & 6.86 & 7.72 & 6.77 & 7.74 \\
\hline$\delta(\mathrm{H} 4)$ & 6.42 & 7.17 & 6.32 & 7.17 \\
\hline$\delta(\mathrm{H} 5)$ & 8.04 & 8.52 & 7.96 & 8.53 \\
\hline$\delta(\mathrm{H} 6)$ & $4.99^{[\mathrm{a}]}$ & 5.10 & $4.90^{[\mathrm{b}]}$ & 5.06 \\
\hline$\delta\left(\mathrm{NSiMe}_{3}\right)$ & 0.23 & - & 0.26 & - \\
\hline$\delta\left(\mathrm{CHMe}_{2}\right)$ & 1.20 & $0.78 / 1.28$ & - & - \\
\hline$\delta\left(\mathrm{CHMe} e_{2}\right)$ & 1.27 & $0.69 / 1.12$ & - & - \\
\hline$\delta(\mathrm{SiMe})$ & - & - & 0.31 & -0.47 \\
\hline$\delta(\mathrm{SiMe})$ & - & - & 0.37 & -0.33 \\
\hline$\delta(\mathrm{Si} t \mathrm{Bu})$ & - & - & 0.96 & 0.49 \\
\hline \multicolumn{5}{|l|}{${ }^{13} \mathrm{C}\left\{{ }^{1} \mathrm{H}\right\}$} \\
\hline$\delta(\mathrm{C} 1)$ & 167.0 & 167.0 & 166.8 & 166.5 \\
\hline$\delta(\mathrm{C} 2)$ & 121.2 & 122.6 & 121.1 & 122.0 \\
\hline$\delta(\mathrm{C} 3)$ & 138.4 & 137.0 & 138.3 & 137.0 \\
\hline$\delta(\mathrm{C} 4)$ & 122.0 & 121.6 & 121.9 & 121.4 \\
\hline$\delta(\mathrm{C} 5)$ & 144.8 & 146.5 & 145.1 & 146.5 \\
\hline$\delta(\mathrm{C} 6)$ & 57.6 & 73.0 & 57.0 & 73.2 \\
\hline$\delta\left(\mathrm{NSiMe}_{3}\right)$ & 6.1 & - & 6.1 & - \\
\hline$\delta\left(\mathrm{CHMe} \mathrm{Me}_{2}\right)$ & 13.9 & 13.5 & - & - \\
\hline$\delta\left(\mathrm{CHMe} e_{2}\right)$ & 19.4 & $18.1 / 18.2$ & - & - \\
\hline$\delta(\mathrm{SiMe})$ & - & - & -4.4 & -4.5 \\
\hline$\delta(\mathrm{SiMe})$ & - & - & -2.0 & -3.5 \\
\hline$\delta\left(\mathrm{SiCMe}_{3}\right)$ & - & - & 20.2 & 18.9 \\
\hline$\delta\left(\mathrm{SiCM}_{3}\right)$ & - & - & 27.4 & 26.2 \\
\hline \multicolumn{5}{|l|}{${ }^{29} \mathrm{Si}\left\{{ }^{1} \mathrm{H}\right\}$} \\
\hline$\delta(\mathrm{Si})$ & 7.86 & 4.98 & 7.94 & 7.49 \\
\hline$\delta\left(\mathrm{NSiMe}_{3}\right)$ & -2.49 & - & -2.55 & - \\
\hline \multicolumn{5}{|l|}{${ }^{119} \mathrm{Sn}\left\{{ }^{1} \mathrm{H}\right\}$} \\
\hline$\delta(\mathrm{Sn})$ & 139.8 & 76.6 & 135.9 & 57.1 \\
\hline
\end{tabular}

Mean value of an $\mathrm{AB}$ spin system, $\delta_{\mathrm{A}}=4.75, \delta_{\mathrm{B}}=5.05,{ }^{2} J_{\mathrm{H}, \mathrm{H}}=18.5 \mathrm{~Hz}$.

Table 5. NMR spectroscopic data of $\mathbf{1 5}$ and $\mathbf{1 6}$; the parameters of $\mathbf{V}$ are included for comparison

\begin{tabular}{lllll}
\hline $\begin{array}{l}\text { Compound } \\
\text { Solvent }\end{array}$ & $\begin{array}{l}\mathbf{V}^{[18]} \\
\mathrm{CCl}_{4}\end{array}$ & $\begin{array}{l}\mathbf{V} \\
{\left[\mathrm{D}_{8}\right] \mathrm{THF}}\end{array}$ & $\begin{array}{l}\mathbf{1 5} \\
{\left[\mathrm{D}_{8}\right] \mathrm{THF}}\end{array}$ & $\begin{array}{l}\mathbf{1 6} \\
{\left[\mathrm{D}_{8}\right] \mathrm{THF}}\end{array}$ \\
\hline$\delta\left(\mathrm{SiMe}_{2}\right)$ & 0.03 & 0.02 & 0.02 & -0.06 \\
$\delta(t \mathrm{Bu})$ & 0.86 & 0.92 & 0.96 & 0.85 \\
$\delta\left(\mathrm{CH}_{2}\right)$ & 3.60 & 3.96 & 3.86 & 4.41 \\
$\delta(\mathrm{Ph})$ & 7.24 & 7.23 & 7.17 & 7.12 \\
$\delta(\mathrm{ZnMe})$ & - & - & - & -0.81 \\
$\delta(\mathrm{NH})$ & n.o. $^{[\mathrm{a}]}$ & n.o. $^{[\mathrm{a}]}$ & - & - \\
\hline
\end{tabular}

[a] Not observed (n.o.).

\section{Experimental Section}

General Remarks: All experiments and manipulations were carried out under argon. Reactions were performed with standard Schlenk techniques and dried, thoroughly deoxygenated solvents. (tertButyldimethylsilyl)(2-pyridylmethyl)amine (I) ${ }^{[1]}$ tin(II) bis[bis(trimethylsilyl)amide], ${ }^{[16-20]}$ (Benzyl)(tert-butyldimethylsilyl)amine, ${ }^{[21]}$ and dimethylmagnesium ${ }^{[43]}$ were prepared according to literature procedures. NMR spectra were recorded with Jeol GSX270 and EX400 spectrometers. A Nicolet 520 FT-IR spectrophotometer was used to record the IR spectra; solid substances were measured in nujol between $\mathrm{KBr}$ plates (vs very strong, s strong, $\mathrm{m}$ medium strong, w weak, vw very weak, sh shoulder). The low carbon and nitrogen values of the elemental analyses are the result of carbide, carbonate, and nitride formation during combustion of the compounds. The NMR parameters are listed in Tables 3-5.

2-(Triisopropylsilylaminomethyl)pyridine [(2-Pyridylmethyl)(triisopropylsilyl)amine] (1): 2-(Aminomethyl)pyridine (3.24 g, $30.0 \mathrm{mmol})$ was dissolved in THF $(20 \mathrm{~mL})$. At $-78^{\circ} \mathrm{C}$, a hexane solution of n-butyllithium $(2.5 \mathrm{M}, 12.0 \mathrm{~mL}, 30.0 \mathrm{mmol})$ was added dropwise. After complete addition, chlorotriisopropylsilane $(6.42 \mathrm{~mL}$, $30.0 \mathrm{mmol})$, dissolved in THF $(5 \mathrm{~mL})$, was added to the still cooled solution. The solution was then slowly warmed to room temperature and all volatile materials were removed under vacuum. Pentane $(15 \mathrm{~mL})$ was added to the remaining pink suspension and all insoluble solids were removed by filtration. After that, all volatile materials were distilled again in vacuo at $120^{\circ} \mathrm{C}$. The remaining oily liquid consisted of analytically pure 1, which turned brown

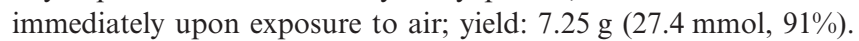
IR: $\tilde{v}=3373 \mathrm{~m}, 3091 \mathrm{w}, 3011 \mathrm{sh}, 2942$ vs, 2892 vs, 2863 vs, 2758 vw, 2722 w, 1700 vw, 1646 vw, 1592 s, 1571 s, 1464 vs, 1434 s, 1407 s, 1387 m, 1382 m, 1366 w, 1342 w, 1319 vw, 1294 vw, 1255 w, 1249 w, 1213 w, 1145 sh, 1125 s, 1094 m, 1084 m, 1070 m, 1047 m, 1013 m, 994 m, 952 vw, 918 w, 883 vs, 841 w, 799 m, 752 s, 728 w, 680 s, $639 \mathrm{~m}, 830 \mathrm{~m}, 602 \mathrm{w}, 553 \mathrm{w}, 502 \mathrm{w}, 462 \mathrm{w}, 404 \mathrm{vw} \mathrm{cm}{ }^{-1}$. MS (EI): $m / z(\%)=265(11), 264(46)\left[\mathrm{M}^{+}\right], 263(100)\left[\mathrm{M}^{+}-\mathrm{H}\right], 223$ (5), 222 (19), 221 (70) $\left[\mathrm{M}^{+}-\mathrm{C}_{3} \mathrm{H}_{7}\right], 220$ (11), 219 (10), 136 (5), 135 (29), 134 (9), 87 (5), 73 (6), 59 (10). $\mathrm{C}_{15} \mathrm{H}_{28} \mathrm{~N}_{2} \mathrm{Si}$ (264.48): calcd. C 68.11, H 10.67, N 10.59; found C 67.19, H 10.29, N 10.72. 
Methylzinc (2-Pyridylmethyl)(triisopropylsilyl)amide (2): A toluene solution of dimethylzinc $(2.0 \mathrm{M}, 11.5 \mathrm{~mL}, 23.0 \mathrm{mmol})$ was added to $1(6.03 \mathrm{~g}, 22.8 \mathrm{mmol})$ in $10 \mathrm{~mL}$ of toluene. After $10 \mathrm{~h}$, the volume of the dark solution was reduced to a few milliliters. At $5{ }^{\circ} \mathrm{C}$, colorless $2(5.10 \mathrm{~g}, 7.41 \mathrm{mmol}, 65 \%$ of the dimer) precipitated. M.p. 72-74 ${ }^{\circ} \mathrm{C}$. IR: $\tilde{v}=3393 \mathrm{vw}, 3138 \mathrm{vw}, 3081 \mathrm{vw}, 2764 \mathrm{vw}, 2726 \mathrm{vw}$, $2269 \mathrm{vw}, 1987 \mathrm{vw}, 1922 \mathrm{vw}, 1868 \mathrm{vw}, 1842 \mathrm{vw}, 1635 \mathrm{vw}, 1603 \mathrm{~s}$, $1571 \mathrm{~m}, 1541 \mathrm{vw}, 1507 \mathrm{vw}, 1486 \mathrm{~m}, 1471 \mathrm{sh}, 1463 \mathrm{~m}, 1431 \mathrm{~s}, 1406$ w, 1389 w, 1383 w, 1357 w, 1320 vw, 1284 m, 1245 w, 1207 vw, 1151 m, 1123 w, 1100 w, 1054 m, 1063 vs, 1016 m, 1011 m, 1003 m, 995 m, 987 m, 972 sh, 917 m, 883 vs, 846 sh, 836 s, 823 m, 803 vs, 794 vs, 754 vs, 723 m, 647 vs, 625 s, 562 w, 508 s, 487 m, $471 \mathrm{~m}, 460$ $\mathrm{m}, 445 \mathrm{~m}, 412 \mathrm{~m} \mathrm{~cm}^{-1}$. MS (EI): $m / z(\%)=341(3)\left[\mathrm{M}^{+} / 2\right], 263$ (7) $\left[\mathrm{M}^{+} / 2-\mathrm{ZnMe}\right], 222$ (21), 221 (100) [263- $\left.\mathrm{C}_{3} \mathrm{H}_{6}\right], 219$ (94), 135 (24), 134 (14). $\left[\mathrm{C}_{16} \mathrm{H}_{30} \mathrm{~N}_{2} \mathrm{SiZn}\right]_{2}$ (687.78): calcd. C 55.88, H 8.79, N 8.15; found C 55.19, H 8.64, N 8.13.

[1,2-Dipyridyl-1,2-bis(triisopropylsilylamido)ethane]bis(methylzinc) (3): A toluene solution of dimethylzinc $(2.0 \mathrm{M}, 7.5 \mathrm{~mL}, 15.0 \mathrm{mmol})$ was added dropwise to a solution of $\mathbf{1}(1.63 \mathrm{~g}, 6.16 \mathrm{mmol})$ in toluene $(5 \mathrm{~mL})$. After $1 \mathrm{~h}$, the green solution was heated under reflux for an additional $20 \mathrm{~h}$. The volume of the solution was then reduced to half of its original amount. At $5{ }^{\circ} \mathrm{C}$ colorless crystals of 3 (1.18 g, $1.72 \mathrm{mmol}, 56 \%$ ) precipitated. M.p. $250{ }^{\circ} \mathrm{C}$ (dec.). IR: $\tilde{v}=3099 \mathrm{~m}, 3077 \mathrm{~m}, 2711 \mathrm{w}, 1993 \mathrm{vw}, 1956 \mathrm{vw}, 1920 \mathrm{vw}, 1601 \mathrm{vs}$, 1571 s, 1474 vs, 1439 vs, 1410 sh, 1388 s, 1382 sh, 1365 w, 1345 m, 1331 w, 1288 s, 1254 s, 1241 sh, 1233 sh, 1210 w, 1158 sh, 1148 vs, 1105 s, 1070 sh, 1050 sh, 1041 vs, 1019 vs, 994 s, 970 w, 918 vs, 884 vs, $847 \mathrm{~m}, 780$ vs, $753 \mathrm{~s}, 721 \mathrm{vw}, 686 \mathrm{sh}, 671$ vs, 654 vs, 644 vs, 631 sh, 607 s, 565 m, 529 vs, 512 vs, 477 s, 417 m, 392 vw, 331 w, 283 $\mathrm{cm}^{-1}$ w. MS (EI): $\mathrm{m} / z(\%)=265(23), 264(81)\left[\mathrm{C}_{15} \mathrm{H}_{28} \mathrm{~N}_{2} \mathrm{Si}\right], 263$ (100) $\left[\mathrm{C}_{15} \mathrm{H}_{27} \mathrm{~N}_{2} \mathrm{Si}\right.$ ], 221 (16) [263- $\mathrm{C}_{3} \mathrm{H}_{6}$ ], 220 (13), 219 (19), 135 (15). $\mathrm{C}_{32} \mathrm{H}_{58} \mathrm{~N}_{4} \mathrm{Si}_{2} \mathrm{Zn}_{2}$ (685.76): calcd. C 56.04, H 8.53, N 8.17; found $\mathrm{C} 55.52, \mathrm{H} 8.40, \mathrm{~N} 7.63$.

Zinc Bis[(2-pyridylmethyl)(triisopropylsilyl)amide] (4): An $n$-hexane solution of $n$-butyllithium $(2.5 \mathrm{M}, 2.8 \mathrm{~mL}, 7.0 \mathrm{mmol})$ was added dropwise to $1(1.85 \mathrm{~g}, 7.0 \mathrm{mmol})$ in THF $(10 \mathrm{~mL})$ at $-78{ }^{\circ} \mathrm{C}$. The solution was then warmed to $0{ }^{\circ} \mathrm{C}$ and zinc(II) bromide $(0.79 \mathrm{~g}$, $3.5 \mathrm{mmol}$ ) was added. After this had been stirred for $10 \mathrm{~h}$, all volatile materials were removed in vacuo at room temperature. From the remaining oil, $0.89 \mathrm{~g}$ of colorless waxy crystals of $4(1.51 \mathrm{mmol}$, $43 \%$ ) were isolated.

[(2-Pyridylmethyl)(triisopropylsilyl)amine- $N, N^{\prime} \mid$ Izinc(II) Chloride (5a): A suspension of zinc(II) chloride $(1.14 \mathrm{~g}, 8.37 \mathrm{mmol})$ in THF $(7 \mathrm{~mL})$ was added to a solution of $\mathbf{1}(2.22 \mathrm{~g}, 8.39 \mathrm{mmol})$ in THF. After 10 min of stirring, the solution was cooled to $-20^{\circ} \mathrm{C}$ and a colorless precipitate of 5a $(2.15 \mathrm{~g}, 5.38 \mathrm{~g}, 64 \%)$ formed. M.p. 203 ${ }^{\circ} \mathrm{C}$. MS (EI): $m / z(\%)=363(77)\left[\mathrm{M}^{+}-\mathrm{Cl}\right], 307$ (16), 263 (13) $\left[\mathrm{M}^{+}-\mathrm{ZnCl}_{2}\right.$ ], 221 (64) [263- $\left.\mathrm{C}_{3} \mathrm{H}_{6}\right], 207$ (30), 155 (27) [SiiPr ${ }_{3}$ $\mathrm{H}_{2}$ ], 154 (100), 136 (72), 105 (33) [263 - HSiiPr 3 ], 91 (43) [263 HNSiiPr ${ }_{3}$ ], 43 (48) $\left[\mathrm{C}_{3} \mathrm{H}_{7}\right] . \mathrm{C}_{15} \mathrm{H}_{28} \mathrm{~N}_{2} \mathrm{SiZnCl}_{2}$ (400.764): calcd. C 44.95, H 7.04, N 6.99; found C 41.84, H 6.45, N 7.32.

[(2-Pyridylmethyl)(triisopropylsilyl)amine- $N, N^{\prime} \mid$ zinc(II) Bromide (5b): Zinc(II) bromide $(1.61 \mathrm{~g}, 7.15 \mathrm{mmol})$ was added at $0{ }^{\circ} \mathrm{C}$ to a solution of $1(1.77 \mathrm{~g}, 7.15 \mathrm{mmol})$ in THF $(10 \mathrm{~mL})$. The brown suspension was stirred for $12 \mathrm{~h}$. The precipitate was collected and washed with several portions of pentane. After drying in vacuo, colorless 5b $(3.12 \mathrm{~g}, 6.36 \mathrm{mmol}, 89 \%)$ was isolated. M.p. $236{ }^{\circ} \mathrm{C}$ (dec.). IR: $\tilde{v}=3216 \mathrm{~m}, 1608 \mathrm{~s}, 1572 \mathrm{~m}, 1473 \mathrm{~m}, 1444 \mathrm{~m}, 1433 \mathrm{~m}$, 1397 w, 1383 m, 1366 vw, 1353 vw, 1284 w, 1253 w, 1227 vw, 1213 w, 1157 vw, 1105 w, 1069 w, 1054 w, 1029 s, 1007 m, 983 m, 964 w, 914 m, 883 s, 842 w, 826 vw, 802 vw, 768 s, 753 s, 723 s, 673 s, 653 w, 605 w, 552 vw, 488 w, 473 vw, 445 w, 414 w, 398 vw, 368 vw, 339 $\mathrm{cm}^{-1}$ vw. MS (EI): $m / z(\%)=409(2)\left[\mathrm{M}^{+}-\mathrm{Br}\right], 263(1)\left[\mathrm{M}^{+}-\right.$ $\left.\mathrm{ZnBr}_{2}\right], \quad 222$ (68), 221 (100) $\left[\begin{array}{lllll}263 & - & \mathrm{C}_{3} \mathrm{H}_{6}\end{array}\right], 136$ (49). $\mathrm{C}_{15} \mathrm{H}_{28} \mathrm{~N}_{2} \mathrm{SiZnBr}_{2}$ (489.664): calcd. C 36.79, H 5.76, N 5.72, $\mathrm{Br}$ 32.63; found C 34.98, H 5.48, N 5.51, Br 33.5.

Magnesium Bis[(2-pyridylmethyl)(triisopropylsilyl)amide] (6): A solution of $1(2.57 \mathrm{~g}, 9.7 \mathrm{mmol})$ in pentane $(50 \mathrm{~mL})$ was cooled to $0{ }^{\circ} \mathrm{C}$. A hexane solution of dibutylmagnesium $(1.0 \mathrm{M}, 4.85 \mathrm{~mL}$, $4.85 \mathrm{mmol}$ ) was added dropwise. After $24 \mathrm{~h}$ of stirring at room temperature, the volume of the solution was reduced to a few milliliters and toluene $(30 \mathrm{~mL})$ was added. Colorless needles of $\mathbf{6}$ (2.53 g, $4.61 \mathrm{mmol}, 95 \%)$ precipitated within hours. Dec. $100{ }^{\circ} \mathrm{C}$ IR: $\tilde{v}=1661 \mathrm{w}, 1630 \mathrm{w}, 1592 \mathrm{~s}, 1570 \mathrm{~m}, 1464 \mathrm{vs}, 1435 \mathrm{~s}, 1407 \mathrm{~s}$, 1382 m, 1366 w, 1343 w, 1319 vw, 1292 vw, 1214 w, 1150 sh, 1124 s, 1094 s, 1072 s, 1047 s, 1013 s, 995 m, 918 w, 882 s, 841 w, 798 s, $753 \mathrm{~m}, 728 \mathrm{w}, 673 \mathrm{~s}, 653 \mathrm{~m}, 639 \mathrm{~m}, 602 \mathrm{~m}, 553 \mathrm{~m}, 501 \mathrm{~m}, 404 \mathrm{~cm}^{-1}$ w. MS (70 eV, EI): $m / z(\%)=503$ (10), 429 (20), 355 (31), 281 (46), 221 (100) $\left[\mathrm{py}-\mathrm{CH}_{2}-\mathrm{Si}_{\mathrm{P}} \mathrm{Pr}_{2}\right.$ ]. $\mathrm{C}_{30} \mathrm{H}_{54} \mathrm{MgN}_{4} \mathrm{Si}_{2}$ (551.26): calcd. C 65.36, H 9.87, N 10.16; found C 59.55, H 9.79, N 8.00.

Methylmagnesium (2-Pyridylmethyl)(triisopropylsilyl)amide (7). Method A: Compound 1 (1.85 g, $7 \mathrm{mmol})$ was added dropwise at 0 ${ }^{\circ} \mathrm{C}$ to a THF/dioxane solution of dimethylmagnesium $(7 \mathrm{~mL}, 1.0$ M), dissolved in $25 \mathrm{~mL}$ of additional THF. After $3 \mathrm{~d}$ of stirring at room temperature, the volume of the solution was reduced and needles of 7 precipitated at $5{ }^{\circ} \mathrm{C}$ in a quantitative yield. - Method B: Compound $6(2.7 \mathrm{mmol})$ was dissolved in THF $(20 \mathrm{~mL})$, and a THF/dioxane solution of dimethylmagnesium $(2.7 \mathrm{~mL}, 1.0 \mathrm{M})$ was added at $0{ }^{\circ} \mathrm{C}$. After stirring for $3 \mathrm{~d}$, the same workup procedure as described for Method A was applied. This compound was characterized by NMR spectroscopy, due to its slow decomposition even at room temperature.

Methylmagnesium (tert-Butyldimethylsilyl)(2-pyridylmethyl)amide (9): Toluene $(10 \mathrm{~mL})$ was added to a THF/dioxane solution of dimethylmagnesium $(1 \mathrm{M}, 2.42 \mathrm{~mL}, 2.42 \mathrm{mmol})$ at $0{ }^{\circ} \mathrm{C}$. (tert-Butyldimethylsilyl)(2-pyridylmethyl)amine $(0.54 \mathrm{~g}, 2.42 \mathrm{mmol})$ was now added dropwise to this solution. After $72 \mathrm{~h}$ of stirring at room temperature, the volume was reduced to a few milliliters. Colorless crystals of $9(0.53 \mathrm{~g}, 1.03 \mathrm{mmol}, 85 \%)$ precipitated at $5{ }^{\circ} \mathrm{C}$. Slow dec. at room temperature. IR: $\tilde{v}=1654 \mathrm{w}, 1601 \mathrm{~s}, 1592 \mathrm{sh}, 1569 \mathrm{~s}$, 1472 s, 1435 s, 1408 m, 1388 m, 1360 w, 1294 vw, 1284 vw, 1251 s, $1210 \mathrm{vw}, 1150 \mathrm{sh}, 1116 \mathrm{~s}, 1100 \mathrm{~s}, 1048 \mathrm{~s}, 1018 \mathrm{~m}, 1007 \mathrm{~m}, 941 \mathrm{~m}$, 908 w, 830 vs, 806 sh, 775 s, 758 sh, 661 m, 643 sh, 629 w, 566 w, $534 \mathrm{~m}, 523 \mathrm{~m}, 497 \mathrm{~m}, 416 \mathrm{w}, 405 \mathrm{w}, 370 \mathrm{w}, 334 \mathrm{~cm}^{-1}$ vw. MS $(70 \mathrm{eV}, \mathrm{EI}): m / z(\%)=221(100)\left[\mathrm{py}-\mathrm{CH}_{2} \mathrm{NSiMe}_{2} t \mathrm{Bu}\right], 207$ (11) $\left[\mathrm{py}-\mathrm{CH}_{2} \mathrm{NSiMe}_{2} t \mathrm{Bu}-\mathrm{Me}\right.$, 191 (4) $\left[\mathrm{py}-\mathrm{CH}_{2} \mathrm{NSiMe}_{2} t \mathrm{Bu}-2\right.$ $\mathrm{Me}$, 165 (83) [py- $\mathrm{CH}_{2} \mathrm{NSiMe}_{2}$ ], 134 (37) [py- $\mathrm{CH}_{2} \mathrm{NSi}$ ], 57 (21) [t $\mathrm{Bu}] . \mathrm{C}_{26} \mathrm{H}_{48} \mathrm{Mg}_{2} \mathrm{~N}_{4} \mathrm{Si}_{2}$ (521.48): calcd. C 59.88, H 9.28, N 10.75; found $\mathrm{C} 58.31, \mathrm{H} 9.26, \mathrm{~N} 10.01 .6$

Bis[(trimethylsilyl)amido]tin(II) (2-Pyridylmethyl)(triisopropylsilyl)amide (11): Compound 1 (1.1 g, $4.1 \mathrm{mmol})$ was added at room temperature to a solution of of tin(II) bis[bis(trimethylsilyl)amide] (1.62 $\mathrm{mL}, 4.1 \mathrm{mmol}$ ) in $20 \mathrm{~mL}$ of toluene. After stirring for $6 \mathrm{~d}$, the volume was reduced to a few milliliters and $5 \mathrm{~mL}$ of THF was added. Cooling to $-20{ }^{\circ} \mathrm{C}$ afforded colorless crystals of $\mathbf{1 1}$. This compound slowly underwent the $\mathrm{C}-\mathrm{C}$ coupling reaction and so only the NMR spectroscopic data are presented in Table 4.

[1,2-Dipyridyl-1,2-bis(triisopropylsilylamido)ethane]tin(II) (12): Tin(II) bis[bis(trimethylsilyl)amide] $(4.5 \mathrm{~mL}, 11.7 \mathrm{mmol})$ was added at room temperature to a solution of $\mathbf{1}(3.1 \mathrm{~g}, 11.7 \mathrm{mmol})$ in toluene $(40 \mathrm{~mL})$. During heating of this solution, the precipitation of tin metal was observed. After decantation, the volume of the solution 
Table 6. Crystallographic data of $\mathbf{2}, \mathbf{3}, \mathbf{8} \cdot 0.5 \mathrm{THF}, \mathbf{9}, \mathbf{9} \cdot \mathbf{1 0}, \mathbf{1 2}, \mathbf{1 2}$, and $\mathbf{1 4}$ as well as details of the structure solution and refinement procedures

\begin{tabular}{|c|c|c|c|c|}
\hline Compound & 2 & 3 & $\mathbf{8} \cdot 0.5 \mathrm{THF}$ & 9 \\
\hline 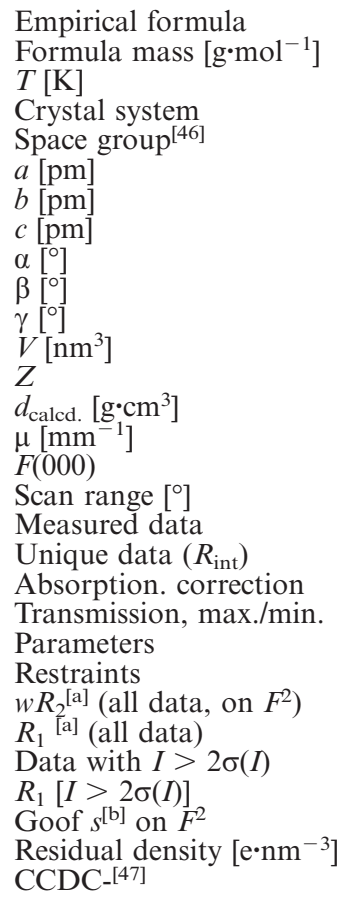 & $\begin{array}{l}\mathrm{C}_{16} \mathrm{H}_{30} \mathrm{~N}_{2} \mathrm{SiZn} \\
343.88 \\
173(2) \\
\text { monoclinic } \\
C 2 / c \\
1619.3(2) \\
1549.2(1) \\
1523.5(2) \\
90 \\
110.38(1) \\
90 \\
3.5828(7) \\
8 \\
1.275 \\
1.432 \\
1472 \\
5.9<2 \theta<50.0 \\
12279 \\
3130(0.1071) \\
\text { none } \\
-/- \\
301 \\
0 \\
0.0813 \\
0.0367 \\
2810 \\
0.0315 \\
1.057 \\
765 /-492 \\
-138790\end{array}$ & $\begin{array}{l}\mathrm{C}_{32} \mathrm{H}_{58} \mathrm{~N}_{4} \mathrm{Si}_{2} \mathrm{Zn}_{2} \\
685.74 \\
293(2) \\
\text { monoclinic } \\
C 2 / c \\
2179.2(5) \\
945.2(1) \\
1855.7(2) \\
90 \\
104.40(1) \\
90 \\
3.702(1) \\
4 \\
1.230 \\
1.385 \\
1464 \\
4.5<2 \theta<48.5 \\
5740 \\
2679(0.0330) \\
\text { semiempirical } \\
1.000 / 0.806 \\
188 \\
0 \\
0.1287 \\
0.0593 \\
2187 \\
0.0457 \\
1.070 \\
628 /-683 \\
-138791\end{array}$ & $\begin{array}{l}\mathrm{C}_{45} \mathrm{H}_{76} \mathrm{Mg}_{2} \mathrm{~N}_{4} \mathrm{O}_{2} \mathrm{Si}_{2} \\
809.90 \\
193(2) \\
\text { triclinic } \\
P \overline{1} \\
1014.8(3) \\
1023.8(3) \\
1168.9(3) \\
79.262(4) \\
79.695(5) \\
84.677(4) \\
1.1717(5) \\
2 \\
1.148 \\
0.142 \\
442 \\
3.6<2 \theta<57.9 \\
6683 \\
3521(0.0228) \\
\mathrm{SADABS} \\
0.986 / 0.972 \\
247 \\
0 \\
0.1950 \\
0.0839 \\
2869 \\
0.0713 \\
1.116 \\
395 /-278 \\
-155098\end{array}$ & $\begin{array}{l}\mathrm{C}_{26} \mathrm{H}_{48} \mathrm{Mg}_{2} \mathrm{~N}_{4} \mathrm{Si}_{2} \\
521.48 \\
193(2) \\
\text { triclinic } \\
P \overline{1} \\
856.7(2) \\
1013.2(3) \\
1056.1(3) \\
71.290(4) \\
83.638(4) \\
68.268(4) \\
0.8065(4) \\
1 \\
1.074 \\
0.168 \\
284 \\
4.1<2 \theta<56.9 \\
4612 \\
2426(0.0281) \\
\mathrm{SADABS} \\
1.000 / 0.538 \\
250 \\
0 \\
0.2038 \\
0.0863 \\
1666 \\
0.0700 \\
1.009 \\
537 /-0.436 \\
-155099\end{array}$ \\
\hline Compound & $9 \cdot 10$ & 12 & $12^{\prime}$ & 14 \\
\hline 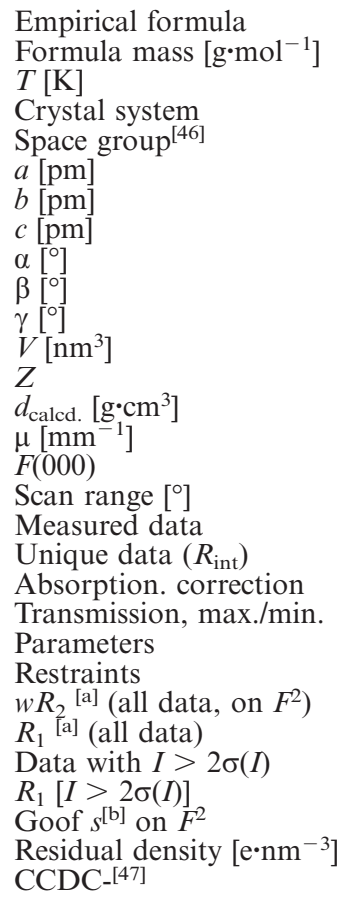 & $\begin{array}{l}\mathrm{C}_{58} \mathrm{H}_{104} \mathrm{Mg}_{4} \mathrm{~N}_{8} \mathrm{O}_{2} \mathrm{Si}_{4} \\
1155.09 \\
193(2) \\
\text { triclinic } \\
P \overline{1} \\
969.42(9) \\
1083.2(1) \\
1769.5(2) \\
100.987(2) \\
105.153(2) \\
97.908(2) \\
1.7258(3) \\
1 \\
1.111 \\
0.165 \\
628 \\
2.4<2 \theta<58.2 \\
10154 \\
5340(0.0320) \\
\mathrm{SADABS} \\
1.000 / 0.810 \\
520 \\
0 \\
0.1453 \\
0.0904 \\
2900 \\
0.0503 \\
0.856 \\
281 /-272 \\
-155100\end{array}$ & $\begin{array}{l}\mathrm{C}_{30} \mathrm{H}_{52} \mathrm{~N}_{4} \mathrm{Si}_{2} \mathrm{Sn} \\
643.64 \\
200(3) \\
\text { triclinic } \\
P \overline{1} \\
1116.7(1) \\
1156.5(1) \\
1410.1(1) \\
89.31(1) \\
80.55(1) \\
67.72(1) \\
1.6582(3) \\
2 \\
1.289 \\
0.867 \\
676 \\
3.8<2 \theta<51.8 \\
13104 \\
5998(0.0250) \\
\text { numerical } \\
0.907 / 0.878 \\
542 \\
0 \\
0.0642 \\
0.0291 \\
5234 \\
0.0224 \\
1.076 \\
517 /-345 \\
-154568\end{array}$ & $\begin{array}{l}\mathrm{C}_{30} \mathrm{H}_{52} \mathrm{~N}_{4} \mathrm{Si}_{2} \mathrm{Sn} \\
643.64 \\
200(3) \\
\text { monoclinic } \\
P 2_{1} / n \\
1660.0(4) \\
892.3(1) \\
2305.9(4) \\
90 \\
101.84(3) \\
90 \\
3.343(1) \\
4 \\
1.279 \\
0.860 \\
1352 \\
4.9<2 \theta<52.0 \\
15298 \\
6166(0.0837) \\
\text { numerical } \\
0.893 / 0.640 \\
334 \\
0 \\
0.1033 \\
0.0543 \\
4832 \\
0.0406 \\
0.938 \\
1028 /-1778 \\
-154569\end{array}$ & $\begin{array}{l}\mathrm{C}_{24} \mathrm{H}_{40} \mathrm{~N}_{4} \mathrm{Si}_{2} \mathrm{Sn} \\
559.47 \\
200(2) \\
\text { monoclinic } \\
P 2_{1} / n \\
1050.15(7) \\
2311.4(2) \\
1202.79(9) \\
90 \\
105.948(8) \\
90 \\
2.8072(4) \\
4 \\
1.324 \\
1.013 \\
1160 \\
5.0<2 \theta<51.8 \\
14494 \\
4314(0.0650) \\
\text { numerical } \\
0.942 / 0.862 \\
440 \\
0 \\
0.0731 \\
0.0507 \\
3190 \\
0.0318 \\
0.920 \\
682 /-396 \\
-154570\end{array}$ \\
\hline
\end{tabular}

[a] Definition of the $R$ values: $R_{1}=\left(\Sigma|| F_{\mathrm{o}}|-| F_{\mathrm{c}} \|\right) / \Sigma\left|F_{\mathrm{o}}\right| ; w R_{2}=\left\{\Sigma\left[w\left(F_{\mathrm{o}}{ }^{2}-F_{\mathrm{c}}{ }^{2}\right)^{2}\right] / \Sigma\left[w\left(F_{\mathrm{o}}{ }^{2}\right)^{2}\right]\right\}^{1 / 2}$ with $w^{-1}=\sigma^{2}\left(F_{\mathrm{o}}{ }^{2}\right)+(a P)^{2}$. ${ }^{\mathrm{b}]} s=$ $\left\{\Sigma\left[w\left(F_{\mathrm{o}}^{2}-F_{\mathrm{c}}^{2}\right)^{2}\right] /\left(N_{\mathrm{o}}-N_{\mathrm{p}}\right)\right\}^{1 / 2}$.

was reduced and $3.57 \mathrm{~g}$ of colorless crystals $(5.56 \mathrm{mmol}, 95 \%)$ precipitated at $-20{ }^{\circ} \mathrm{C}$. M.p. $102{ }^{\circ} \mathrm{C}$. IR: $\tilde{v}=1690 \mathrm{vw}, 1663 \mathrm{vw}, 1621$ vw, 1599 vs, 1588 vs, 1565 vs, 1474 s, 1432 vs, 1387 s, 1358 m, 1335 s, 1285 s, 1268 m, 1248 s, 1228 sh, $1207 \mathrm{vw}, 1158$ m, 1140 m, 1105 sh, 1086 vs, br, 1063 vs, br, 1045 vs, br, 1011 vs, 994 vs, 950 vs, 918 s, 896 sh, 883 vs, 861 vs, 820 s, 781 vs, 749 vs, 681 vs, 661 vs, 640 vs, 624 vs, 610 vs, $571 \mathrm{~m}, 538 \mathrm{~m}, 524$ vs, 508 vs, $486 \mathrm{~m}, 476 \mathrm{~m}, 443$ s, $421 \mathrm{~m}, 405 \mathrm{~s}, 315 \mathrm{w}, 284 \mathrm{~cm}^{-1} \mathrm{~m}$. MS (70 eV, EI): $\mathrm{m} / \mathrm{z}(\%)=644$ 
(0.2) $\left[\mathrm{M}^{+}\right], 601(0.2)\left[\mathrm{M}^{+}-i \operatorname{Pr}\right], 527(0.2)\left[\mathrm{M}^{+}-\mathrm{Sn}\right], 483$ (1.1) $\left[\mathrm{M}^{+}-\mathrm{Sn}-i \mathrm{Pr}\right], 448(0.2)\left[\mathrm{M}^{+}-\mathrm{Sn}-\mathrm{py}\right], 382(32)\left[\mathrm{M}^{+}-\right.$ py-CHNSi $\left.(i \mathrm{Pr})_{3}\right], \quad 263 \quad(100) \quad\left[\right.$ py $\left.-\mathrm{CHNSi}(i \mathrm{Pr})_{3}\right], \quad 219 \quad(100)$ [py-CHNSi $(i \operatorname{Pr})_{2}$ ], 134 (63). $\mathrm{C}_{30} \mathrm{H}_{52} \mathrm{~N}_{4} \mathrm{Si}_{2} \mathrm{Sn}$ (643.64): calcd. C 55.97, H 8.14, N 8.70; found C 55.97, H 8.33, N 8.54.

[Bis(trimethylsilyl)amido]tin(II) (tert-Butyldimethylsilyl)(2-pyridylmethyl)amide (13): Amine I (0.77 g, $3.46 \mathrm{mmol})$ was dissolved in toluene $(20 \mathrm{~mL})$. At room temperature, tin(II) bis[bis(trimethylsilyl)amide] (1.35 mL $3.46 \mathrm{mmol})$ was added. After $6 \mathrm{~d}$ of stirring, the volume of the solution was reduced and $\mathbf{1 3}$ precipitated quantitatively at $5{ }^{\circ} \mathrm{C}$ as a polycrystalline material, which decomposed slowly even at room temperature. IR: $\tilde{v}=2953$ vs, 2894 vs, 2850 vs, 2799 w, $1993 \mathrm{vw}, 1905 \mathrm{vw}, 1854 \mathrm{vw}, 1608 \mathrm{~s}, 1570 \mathrm{~m}, 1505 \mathrm{sh}, 1485 \mathrm{~m}$, $1470 \mathrm{~s}, 1440 \mathrm{~s}, 1420 \mathrm{~m}, 1387 \mathrm{~m}, 1358 \mathrm{w}, 1281 \mathrm{~s}, 1251 \mathrm{vs}, 1180 \mathrm{w}$, 1155 m, 1099 s, 1050 s, 1005 m, 993 m, 946 vs, 901 vs, 863 vs, 832 vs, 777 s, 757 s, 716 m, 700 m, 668 vs, 582 vw, 490 w, 463 vw, 416 vw, $361 \mathrm{w}$.

[1,2-Bis(tert-butyldimethylsilylamido)-1,2-dipyridylethane]tin(II) (14): Tin(II) bis[bis(trimethylsilyl)amide] (2 $\mathrm{mL}, 5.12 \mathrm{mmol})$ was added at room temperature to a solution of $\mathbf{I}(1.14 \mathrm{~g}, 5.12 \mathrm{mmol})$ in toluene $(20 \mathrm{~mL})$. Heating for $3 \mathrm{~d}$ at $80{ }^{\circ} \mathrm{C}$ resulted in the precipitation of tin metal. After removal of the metal, the volume of the solution was reduced. At $-20^{\circ} \mathrm{C}, 1.40 \mathrm{~g}$ of colorless crystals of $\mathbf{1 4}$ (2.55 mmol, 98\%) precipitated. M.p. $143{ }^{\circ} \mathrm{C}$. IR: $\tilde{v}=1684 \mathrm{sh}, 1656$ w, 1601 s, 1587 s, 1567 s, 1470 vs, 1462 vs, 1440 s, 1432 s, 1416 m, 1410 m, 1356 m, 1338 w, 1319 m, 1285 m, 1252 vs, 1208 sh, 1154 m, $1141 \mathrm{~m}, 1102 \mathrm{~s}, 1090 \mathrm{vs}, 1071 \mathrm{vs}, 1046 \mathrm{~s}, 1014 \mathrm{~s}, 1005 \mathrm{~s}, 994 \mathrm{~s}$, 969 vs, 958 s, 937 m, 922 s, 903 s, 886 vs, 829 vs, 807 vs, 776 vs, 767 vs, 748 vs, 673 m, 660 s, 641 s, 622 m, 606 s, 573 w, 545 m, 522 s, $490 \mathrm{~m}, 456 \mathrm{w}, 415 \mathrm{~m}, 393 \mathrm{~m}, 371 \mathrm{w}, 357 \mathrm{w}, 335 \mathrm{vw}, 323 \mathrm{vw}, 300$ vw, $283 \mathrm{~cm}^{-1}$ w. MS (70 eV, EI): $m / z(\%)=441(21)\left[\mathrm{M}^{+}-\mathrm{Sn}\right]$, $383(18)\left[\mathrm{M}^{+}-\mathrm{Sn}-t \mathrm{Bu}\right], 356(26)\left[\mathrm{M}^{+}-\right.$py], 252 (30), 221 (100) $\left[{ }_{1} / \mathrm{M}^{+}-\mathrm{Sn}\right], 163(68)\left[{ }_{1}^{1} / \mathrm{M}^{+}-\mathrm{Sn}-t \mathrm{Bu}\right], 149(28)\left[{ }^{1} /{ }_{2} \mathrm{M}^{+}-\mathrm{Sn}\right.$ $-t \mathrm{Bu}-\mathrm{Me}], 107$ (13), 75 (100), 59 (11) $[t \mathrm{Bu}] . \mathrm{C}_{24} \mathrm{H}_{40} \mathrm{~N}_{4} \mathrm{Si}_{2} \mathrm{Sn}$ (559.48): calcd. C 51.52, H 7.21, N 10.01, found C 51.29, H 7.45, N 9.72 .

Zinc Bis[(benzyl)(tert-butyldimethylsilyl)amide] (15): A hexane solution of butyllithium $(2.5 \mathrm{M}, 3.95 \mathrm{~mL}, 9.88 \mathrm{mmol})$ was added dropwise at $-78{ }^{\circ} \mathrm{C}$ to (tert-butyldimethylsilyl)(2-pyridylmethyl)amine $(1.93 \mathrm{~g}, 8.99 \mathrm{mmol})$ in pentane $(10 \mathrm{~mL})$. During the warm-up, a colorless solid precipitated. This suspension was stirred at room temperature for an additional $8 \mathrm{~h}$. At $-18{ }^{\circ} \mathrm{C}$ the lithium salt crystallized and was isolated by decanting the mother liquor. This crystalline material was redissolved in pentane $(25 \mathrm{~mL})$ at $0{ }^{\circ} \mathrm{C}$. Zinc(II) bromide $(1.00 \mathrm{~g}, 4.44 \mathrm{mmol})$ was then added and the solution was stirred at room temperature for several days. A colorless precipitate formed and was separated. The volume of the solution was reduced to afford an oily residue. At $-18{ }^{\circ} \mathrm{C}, 1.25 \mathrm{~g}$ of colorless crystals of $15(2.47 \mathrm{mmol}, 55 \%)$ grew in the oil. M.p. $65{ }^{\circ} \mathrm{C}$. ${ }^{1} \mathrm{H}$ NMR ([D $\mathrm{D}_{6}$ benzene): $\delta=7.17(\mathrm{~m}, 5 \mathrm{H}, \mathrm{Ph}), 3.86\left(\mathrm{~s}, 2 \mathrm{H}, \mathrm{CH}_{2}\right), 0.96(\mathrm{~s}$, $9 \mathrm{H}, t \mathrm{Bu}), 0.02\left(\mathrm{~s}, 6 \mathrm{H}, \mathrm{SiCH}_{3}\right) \cdot{ }^{13} \mathrm{C}\left\{{ }^{1} \mathrm{H}\right\}$ NMR ([D 6 benzene): $\delta=$ 148.21 ( $\left.\mathrm{C}_{\mathrm{q}}, \mathrm{Ph}\right), 129.36(\mathrm{Ph}), 127.29(\mathrm{Ph}), 126.79(\mathrm{Ph}), 51.92\left(\mathrm{CH}_{2}\right)$, $27.31\left(\mathrm{CCH}_{3}\right), 19.76\left(\mathrm{CCH}_{3}\right),-3.63\left(\mathrm{SiCH}_{3}\right) .{ }^{29} \mathrm{Si}\left\{{ }^{1} \mathrm{H}\right\} \mathrm{NMR}$ ([D 6 benzene): $\delta=7.05$. IR: $\tilde{v}=3409 \mathrm{vw}, 3087 \mathrm{vw}, 3067 \mathrm{w}, 3028$ w, 2954 vs, 2926 vs, 2899 vs, 2883 vs, 2855 vs, 2806 sh, 2799 w, 2718 vw, 1680 sh, 1650 vs, 1619 sh, 1605 m, 1583 m, 1568 sh, 1537 vw, 1509 sh, 1494 m, 1471 vs, 1463 s, 1453 s, 1389 s, 1361 m, 1306 w, 1292 vw, 1252 vs, 1209 w, 1199 w, 1166 vw, 1115 s, 1102 s, 1070 m, 1028 m, 1007 m, 973 vw, 938 w, 912 vw, 898 w, 845 vs, 831 s, 814 s, 774 vs, 749 s, 728 m, 696 s, 663 m, 586 w, 561 w, 482 m, 420 w, $369 \mathrm{w}, 334 \mathrm{~cm}^{-1}$ vw. MS (EI): $m / z(\%)=504(1)\left[\mathrm{M}^{+}\right], 489(1)$ $\left[\mathrm{M}^{+}-\mathrm{Me}\right], 447$ (47) $\left[\mathrm{M}^{+}-t \mathrm{Bu}\right], 367$ (14), 353 (29), 165 (17)
$\left[\mathrm{C}_{13} \mathrm{H}_{22} \mathrm{NSi}-\mathrm{C}_{4} \mathrm{H}_{8}\right], 164(100)\left[\mathrm{C}_{13} \mathrm{H}_{22} \mathrm{NSi}-t \mathrm{Bu}\right], 162$ (32), 148 (13), 135 (58), 91 (29) [Bzl], 73 (25) [ $\mathrm{SiMe}_{2} t \mathrm{Bu}-\mathrm{C}_{3} \mathrm{H}_{6}$ ], 59 (41) [Si$\mathrm{Me}_{2} t \mathrm{Bu}-\mathrm{C}_{4} \mathrm{H}_{8}$ ], 57 (13) [ $\left.t \mathrm{Bu}\right] . \mathrm{C}_{26} \mathrm{H}_{44} \mathrm{~N}_{2} \mathrm{Si}_{2} \mathrm{Zn}$ (506.225): calcd. C 61.69, H 8.76, N 5.54, found C 61.95, H 9.17, N 5.42.

Crystal Structure Determinations: Data were collected with a STOE-IPDS diffractometer (compounds 2, 12, 12', and 14) and a Siemens P4 diffractometer with a Siemens SMART-CCD area detector (compounds $\mathbf{8} \cdot 0.5 \mathrm{THF}, \mathbf{9}$, and $\mathbf{9} \cdot \mathbf{1 0}$ ) using oil-coated, rapidly cooled single crystals. ${ }^{[4,45]}$ The data for $\mathbf{3}$ were collected with a Nonius CAD4 diffractometer using a single crystal sealed in a glass capillary. In all cases, graphite-monochromated Mo- $K_{\alpha}$ radiation $(\lambda=71.073 \mathrm{pm})$ was used. Crystallographic parameters, details of data collection, and refinement procedures are summarized in Table 6.

The structures were solved by direct methods and refined with the software packages SHELXL-93 and SHELXL-97. ${ }^{[48]}$ Neutral scattering factors were taken from Cromer and Mann ${ }^{[49]}$ and those for the hydrogen atoms from Stewart et al. ${ }^{[50]}$ The non-hydrogen atoms were refined anisotropically. The $\mathrm{H}$ atoms were considered with a riding model under restriction of ideal symmetry at the corresponding carbon atoms or refined isotropically. Crystallographic details can be obtained from the Cambridge Data Centre quoting the CCDC numbers given in Table 6. ${ }^{[47]}$

\section{Acknowledgments}

This work was financially supported by the Deutsche Forschungsgemeinschaft, Bonn, and the Fonds der Chemischen Industrie, Frankfurt/Main. We thank Mr. S. Correll for performing the X-ray powder diffraction experiments of precipitated zinc and tin metals and Dr. A. Lötz for the ESR experiments. Prof. G. van Koten (Utrecht University) provided helpful suggestions and contributions to the discussion of the mechanism. T. B. wishes to express his gratitude to the Fonds der Chemischen Industrie for a Ph.D. scholarship.

[1] M. Westerhausen, T. Bollwein, N. Makropoulos, T. M. Rotter, T. Habereder, M. Suter, H. Nöth, Eur. J. Inorg. Chem. 2001, $851-857$.

[2] G. van Koten, J. T. B. H. Jastrzebski, K. Vrieze, J. Organomet. Chem. 1983, 250, 49-61.

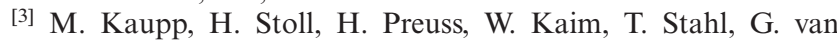
Koten, E. Wissing, W. J. J. Smeets, A. L. Spek, J. Am. Chem. Soc. 1991, 113, 5606-5618.

[4] E. Wissing, M. Kaupp, J. Boersma, A. L. Spek, G. van Koten, Organometallics 1994, 13, 2349-2356.

${ }^{[5]}$ E. Wissing, K. van Gorp, J. Boersma, G. van Koten, Inorg. Chim. Acta 1994, 220, 55-61.

${ }^{[6]}$ E. Wissing, S. van der Linden, E. Rijnberg, J. Boersma, W. J. J. Smeets, A. L. Spek, G. van Koten, Organometallics 1994, 13, 2602-2608.

[7] E. Wissing, E. Rijnberg, P. A. van der Schaaf, K. van Gorp, J. Boersma, G. van Koten, Organometallics 1994, 13, 2609-2615.

${ }^{[8]}$ J. T. B. H. Jastrzebski, J. M. Klerks, G. van Koten, K. Vrieze, J. Organomet. Chem. 1981, 210, C49-C53.

${ }^{[9]}$ A. L. Spek, J. T. B. H. Jastrzebski, G. van Koten, Acta Crystallogr., Sect. C 1987, 43, 2006-2007.

${ }^{[10]}$ M. Westerhausen, T. Bollwein, K. Polborn, Z. Naturforsch., Teil B 2000, 55, 51-59.

[11] J. Emsley, The Elements, W. de Gruyter, Berlin, 1994.

${ }^{[12]}$ A. Boudier, L. A. Bromm, M. Lotz, P. Knochel, Angew. Chem. 2000, 112, 4584-4606; Angew. Chem. Int. Ed. 2000, 39, $4414-4435$

${ }^{[13]}$ H. Gornitzka, D. Stalke, Angew. Chem. 1994, 106, 695-698; Angew. Chem. Int. Ed. Engl. 1994, 33, 693-696.

${ }^{[14]}$ H. Gornitzka, D. Stalke, Organometallics 1994, 13, 4398-4405. 
${ }^{[15]}$ T. Kottke, D. Stalke, Chem. Ber./Recueil 1997, 130, 1365-1374.

${ }^{[16]}$ D. H. Harris, M. F. Lappert, J. Chem. Soc., Chem. Commun. 1974, 895-896.

${ }^{[17]}$ C. D. Schaeffer, J. J. Zuckerman, J. Am. Chem. Soc. 1974, 96, $7160-7162$.

${ }^{[18]}$ M. J. S. Gynane, D. H. Harris, M. F. Lappert, P. P. Power, P. Rivière, M. Rivière-Baudet, J. Chem. Soc., Dalton Trans. 1977, 2004-2009.

${ }^{[19]}$ P. J. Corvan, J. J. Zuckerman, Inorg. Chim. Acta 1979, 34, $255-258$.

${ }^{[20]}$ N. Auner, U. Klingebiel, Synthetic Methods of Organometallic and Inorganic Chemistry (Herrmann/Brauer), Thieme, New York, 1996, vol. 2, p. 280, 288.

${ }^{[21]}$ J. R. Bowser, J. F. Bringley, Synth. React. Inorg. Met. -Org. Chem. 1985, 15, 897-905.

${ }^{[22]}$ T. Bollwein, Ph.D. Thesis, University of Munich (LMU), 2001.

${ }^{[23]}$ I. B. Gorrell, A. Looney, G. Parkin, J. Am. Chem. Soc. 1990, 112, 4068-4069.

${ }^{[24]}$ M. G. Davidson, D. Elilio, S. L. Less, A. Martín, P. R. Raithby, R. Snaith, D. S. Wright, Organometallics 1993, 12, 1-3.

${ }^{[25]}$ M. M. Olmstead, W. J. Grigsby, D. R. Chacon, T. Hascall, P. P. Power, Inorg. Chim. Acta 1996, 251, 273-284.

${ }^{[26]}$ M. Westerhausen, T. Bollwein, A. Pfitzner, T. Nilges, H.-J. Deiseroth, Inorg. Chim. Acta 2001, 312, 239-244.

${ }^{[27]}$ M. A. Khan, D. G. Tuck, Acta Crystallogr., Sect. C 1984, 40, $60-62$.

${ }^{[28]}$ A. L. Spek, Cryst. Struct. Commun. 1982, 11, 1621.

${ }^{[29]}$ M. Westerhausen, B. Rademacher, W. Schwarz, J. Organomet. Chem. 1992, 427, 275-287.

${ }^{[30]}$ M. D. Levin, P. Kaszynski, J. Michl, Chem. Rev. 2000, 100, $169-234$.

${ }^{[31]}$ P. R. Markies, O. S. Akkerman, F. Bickelhaupt, W. J. J. Smeets, A. L. Spek, Adv. Organomet. Chem. 1991, 32, 147-226.

${ }^{[32]}$ C. E. Holloway, M. Melnik, J. Organomet. Chem. 1994, 465, $1-63$.

[33] J. March, Advanced Organic Chemistry, 3rd ed., Wiley, New York, 1985, p. 19
${ }^{[34]}$ J. E. Huheey, Anorganische Chemie: Prinzipen von Struktur und Reaktivität, W. de Gruyter, Berlin, 1988, p. 278-279.

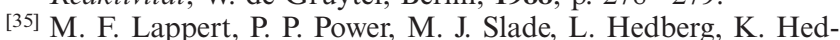
berg, V. Schomaker, J. Chem. Soc., Chem. Commun. 1979, $369-370$.

${ }^{[36]}$ T. Fjeldberg, H. Hope, M. F. Lappert, P. P. Power, A. J. Thorne, J. Chem. Soc., Chem. Commun. 1983, 639-641.

${ }^{[37]}$ T. Fjeldberg, A. Haaland, B. E. R. Schilling, M. F. Lappert, A. J. Thorne, J. Chem. Soc., Dalton Trans. 1986, 1551-1556.

${ }^{[38]}$ B. S. Jolly, M. F. Lappert, L. M. Engelhardt, A. H. White, C. L. Raston, J. Chem. Soc., Dalton Trans. 1993, 2653-2663.

${ }^{[39]}$ U. Kilimann, M. Noltemeyer, F. T. Edelmann, J. Organomet. Chem. 1993, 443, 35-42.

${ }^{[40]}$ M. F. Lappert, Main Group Met. Chem. 1994, 17, 183-207.

${ }^{[41]}$ B. Wrackmeyer, J. Magn. Reson. 1985, 61, 536-539.

${ }^{[42]}$ B. Wrackmeyer, K. Horchler, H. Zhou, Spectrochim. Acta 1990, 46A, 809-816.

${ }^{[43]}$ W. Strohmeier, F. Seifert, Chem. Ber. 1961, 94, 2356; see also: E. Weiss, J. Organomet. Chem. 1964, 2, 314-321.

${ }^{[44]}$ T. Kottke, D. Stalke, J. Appl. Crystallogr. 1993, 26, 615-619.

${ }^{[45]}$ D. Stalke, Chem. Soc. Rev. 1998, 27, 171-178.

${ }^{[46]}$ T. Hahn (Ed.), International Tables for Crystallography, vol. A ("Space Group Symmetry"), 2nd ed., D. Reidel, Dordrecht, 1984.

[47] Crystallographic data (excluding structure factors) for the crystal structures have been deposited with the Cambridge Crystallographic Data Centre as supplementary publications as listed in Table 6. Copies of the data can be obtained on application to CCDC, 12 Union Road, Cambridge CB2 1EZ, UK [Fax: int. code + 44-1223/336-033; E-mail: deposit@ccdc.cam.ac.uk].

${ }^{[48]}$ G. M. Sheldrick, SHELXL-93, Universität Göttingen, 1993; SHELXL-97, Universität Göttingen, 1997.

${ }^{[49]}$ D. T. Cromer, J. B. Mann, Acta Crystallogr. 1968, 24, 321-324.

${ }^{[50]}$ R. F. Stewart, E. R. Davidson, W. T. Simpson, J. Chem. Phys. 1965, 42, 3175-3187.

Received January 10, 2001

[I01012] 